\title{
A comparative assessment of electrification strategies for industrial sites: Case of milk powder production
}

Bühler, Fabian; Zühlsdorf, Benjamin; Nguyen, Tuong-Van; Elmegaard, Brian

Published in:

Applied Energy

Link to article, DOI:

10.1016/j.apenergy.2019.05.071

Publication date:

2019

Document Version

Peer reviewed version

Link back to DTU Orbit

Citation (APA):

Bühler, F., Zühlsdorf, B., Nguyen, T-V., \& Elmegaard, B. (2019). A comparative assessment of electrification strategies for industrial sites: Case of milk powder production. Applied Energy, 250, 1383-1401.

https://doi.org/10.1016/j.apenergy.2019.05.071

\section{General rights}

Copyright and moral rights for the publications made accessible in the public portal are retained by the authors and/or other copyright owners and it is a condition of accessing publications that users recognise and abide by the legal requirements associated with these rights.

- Users may download and print one copy of any publication from the public portal for the purpose of private study or research.

- You may not further distribute the material or use it for any profit-making activity or commercial gain

- You may freely distribute the URL identifying the publication in the public portal 


\title{
A comparative assessment of electrification strategies for industrial sites: Case of milk powder production
}

\author{
Fabian Bühler ${ }^{* 1}$, Benjamin Zühlsdorf ${ }^{1}$, Tuong-Van Nguyen ${ }^{1}$ and Brian Elmegaard ${ }^{1}$ \\ ${ }^{1}$ Department of Mechanical Engineering, Technical University of Denmark, Nils Koppels Allé, Bygning 403, 2800 Kgs. Lyngby, \\ Denmark
}

\begin{abstract}
Denmark has the ambitious plan of being independent from fossil fuels by 2050 and to run the entire energy system based on renewable energy sources. One of the most likely scenarios is a bigger deployment of wind farms and a massive electrification of the industry and transportation sectors. In 2016, the industry sector accounted for $20 \%$ of the final energy use, which was by more than $50 \%$ covered directly with fossil fuels. Electrification is a promising way for decarbonizing this sector but it will require significant economic investments and changes of the infrastructures. In this work, several strategies for electrifying industrial processes, based on the integration of heat pumps and electric heaters are presented. They were compared using energy, exergy, economic and environmental performance indicators. The production of milk powder was taken as a case study, as current factories are energy-intensive and require high-temperature heat generated by natural gas combustion. The highest energy efficiency and lowest exergy destruction was found for a system using a central heat pump system, with energy savings of $65 \%$. The implementation of decentralised heat pumps that exchange heat between process streams and electric heaters, results in smaller reductions of only $56 \%$. These two systems are likely profitable based on the energy price forecasts from 2020, but the decentral system allows for a gradual implementation of the most cost-effective measures.
\end{abstract}

\section{Highlights}

- Strategies for electrification of industrial sites to reduce fossil fuel use

- Energy, exergy, environmental and economic analysis of electrification scenarios

- Evaluation of an all-electric milk powder production with heat pump integration

- Comparison of scenarios with future energy prices and emissions

- Quantification of cost and emission reductions through heat pump integration

Keywords: Electrification, industry, economic analysis, energy efficiency, heat pump, exergy analysis.

\section{Introduction}

The Danish energy system will become independent of fossil fuels and largely based on electricity from renewable sources, following the latest national energy agreement [1]. The last energy plan set by the Danish government aims at having $50 \%$ of the final energy demand covered by renewables in 2030 and focuses as well on energy efficiency improvements. Around $20 \%$ of the energy in 2016 was used in the industry, and out of this almost $70 \%$ was used for the manufacturing industry [2]. The manufacturing industry in Denmark is dominated by food industries, such as dairy and beverage production, and the production of building materials and pharmaceuticals. More than 50 \% (70 PJ) of the energy used in manufacturing industries was derived from fossil fuels, mostly for heat supply purposes. Around $35 \%$ was electrical energy which is an

\footnotetext{
${ }^{*}$ Corresponding Author

Email address: Fabian Bühler (fabuhl@mek.dtu.dk)
} 
increase of $6.7 \%$-points since 1990. However, the majority of the fossil fuels in the manufacturing industry was used for supply of process heat. In future energy scenarios, which are based on a higher share of wind energy, a large part of the low-temperature heat $\left(<100^{\circ} \mathrm{C}\right)$ should be covered by heat pumps, while the majority of the medium $\left(100^{\circ} \mathrm{C}\right.$ to $\left.200^{\circ} \mathrm{C}\right)$ and high temperature heat $\left(>200^{\circ} \mathrm{C}\right)$ would be supplied by electric heaters or biomass boilers [3]. A more efficient use of electricity is required to reduce the share of biomass in medium- and high-temperature processes [1], while the utilization of high-temperature heat pumps is a promising approach. There are several benefits for industries through electrification [4], such as faster, more precise and more efficient heating. A report by the National Renewable Energy Laboratory [5] investigated the electric technology adoption for the United States. While the transport sector experienced the greatest adoption rate in the investigated scenarios, the industry sector was found to use electric technologies primarily when also productivity benefits were present. The authors assumed that industrial end uses experience many barriers to electrification that are associated with profitability and production disruptions. Wiese and Baldini [6] created a conceptual model of the industry sector, focusing on the energy end-use processes and measures for fossil fuel reductions. Together with fuel substitution and energy efficiency measures, electrification is seen as a viable option to reduce fossil fuel use. The authors point out that for many industries the shift to electricity is challenging, especially if processes are highly based on gas use (e.g. in slaughterhouses and for production of building materials). A more detailed analysis is thus recommended to find the optimal substitution approach. These works show that electrifying the industry is challenging and requires more detailed case studies due to the heterogeneity of this sector compared to transport and households.

The production of milk products is an important business area and constitutes a high share of agricultural products [7]. Milk powder is a particularly energy intensive product, as raw milk requires thermal treatment, cooling, and water removal in evaporators and dryers [8]. Raw milk processing requires primary energy of between $0.61 \mathrm{kWh}$ per ton of milk in France and $0.36 \mathrm{kWh}$ per ton of milk in the United Kingdom in 2000. This large difference results from different levels of adaptation of energy efficiency measures, but more importantly on the share of energy intensive milk products. For instance, milk powder requires $3.08 \mathrm{MWh}$ per ton of powder.

An exergy analysis of a milk powder factory was performed by Yildirim and Genc [9], where the use of geothermal energy for preheating the drying air was studied. A similar analysis [10] was performed by the same authors for the milk pasteurisation process, where a vapour absorption cycle was included for cooling the milk. An exergy and advanced exergy analysis was performed by Bühler et al. [11] for a Danish milk powder factory for which the use of solar thermal energy was further analysed [12]. The analyses showed that the milk powder production has large inefficiencies in the utility system and spray drying section, which can however only be slightly reduced through process integration. The reductions would become more efficient by installing a new utility system. Integrating solar thermal systems directly into the production would be economically feasible, but it would only replace a small fraction of the total heating demand.

The integration of heat pump in a spray dryer for milk powder for the recovery of excess heat from the drying air was studied by Zühlsdorf et al. [13]. The high-temperature heat pump preheated the air to up to $125^{\circ} \mathrm{C}$, reaching a coefficient of performance (COP) of above 3. The use of a high-temperature heat pump with district heat as the source for steam generation in a dairy factory was analysed by Tveit [14]. This work proved the technical feasibility and environmental benefits of such a system.

A factory to produce milk powder with an ultra-low energy input was studied by Walmsley et al. [15]. Their approach applied a total site analysis, the implementation of evaporators with mechanical vapour recompression (MVR) and excess heat recovery of the drying air. From the initial design it was possible to reduce energy use by more than $50 \%$ to a thermal energy use of $0.71 \mathrm{MWh}$ per ton of powder. The design of milk powder production plants in New Zealand and California, based on a $100 \%$ renewable energy supply, was studied by Walmsley et al. [16]. Depending on the available energy resources the aim could be accomplished by (i) geothermal steam and renewable electricity for the MVR, (ii) a biomass boiler with a twostage ammonia heat pump using the boiler flue gases and (iii) with biogas and solar thermal energy. The case 
of a slaughterhouse only using electric energy was presented in the Netherlands [17], where heat is recovered and generated by heat pumps and electric boilers. However, temperatures stated in this process are below $90{ }^{\circ} \mathrm{C}$. Wiertzema et al. [18] studied electrification options for industrial processes using a bottom up methodology and applied it to an oil refinery. The study concluded that detailed process models are required to predict changes to energy use and that heat available at the plant is often in competition with electricity use. Also for an oil refinery, Berghout et al. [19] investigated pathways for reducing greenhouse gas emissions. While electrification was not specifically included, the presented method is applicable to it and useful for evaluating emission reduction strategies of industrial sites. Chen et al. [20] studied the electrification of methanol production, where the indirect electrification through alternative feedstocks and direct electrification through heat pumps were investigated. The direct electrification was found to be insignificant compared to the indirect one, as only parts of the heat demand can be converted to electricity.

With respect to milk powder production, research has focused on analysing and optimising the processes, and on how to integrate renewable energy sources in specific cases. Covering the thermal energy demands of milk powder production solely with electric energy has not been investigated yet, although lower electricity costs and a high share of wind, hydro or solar power could turn it profitable from economic and environmental perspectives. The need of high-temperature heat in the drying process makes this electrification scenario challenging. Furthermore, the optimal electrification strategy for an existing factory needs to be determined to increase the system energy efficiency at lower costs. While many studies address strategies to lower fuel related $\mathrm{CO}_{2}$-emissions in industries, the accomplishment of this goal through electrification is not sufficiently studied. Research has focused on energy efficiency and fuel substitution at industrial sites $[9,15,16]$ or on system studies $[3,5,6]$ for the electrification of a country, but little work has been performed on implementing an optimised all-electric production site.

The aim of this paper is to develop and analyse different approaches for electrifying the energy supply of industrial sites with process heat demands at temperatures up to $210^{\circ} \mathrm{C}$. Different electrification strategies were developed and demonstrated for the case of a milk powder production facility. At first, the production system was modelled and different electrification strategies, with different levels of retrofit, were sketched. They also differ by the level of integration between the processes and the utility system. The current and the electrified dairy production systems are modelled and optimised using energy, exergy and process integration methods. The development of the all-electric factory includes the integration of heat pumps by taking the temperature levels of heating and cooling demands into account. The evaluation and comparison of the systems were based on indicators such as exergy destruction, specific energy use, economic (net present value and operating costs) and environmental parameters $\left(\mathrm{CO}_{2}\right.$-emissions). The novelty of this work lies in (i) the feasibility analysis of electrifying an industrial site, (ii) the development and evaluation of central and de-central electrification options, (iii) the quantification of the thermodynamic, economic and environmental benefits of electrification in the industry and (iv) the investigation of economic frameworks for electrification directed to policy making.

\section{Methods}

This section presents the method and concepts used for the modelling, analysis and evaluation of the industrial processes for which different electrification strategies were considered. First, the case study of the dairy production system and its main components are introduced, followed by the overall methods, the electrification strategy and considered scenarios. The last two sections describe the modelling approach and basis of the economic analysis.

\subsection{Dairy production system}

The dairy production system consists of three production units, namely the milk treatment $(\mathrm{H})$, evaporation (E) and spray drying (S) section. In addition to the production units, the current plant has a hot and cold utility system satisfying the cooling and heating demands. The production system under study is shown in Figure 1. The incoming raw milk (M1) is preheated, separated into cream (C1) and skim milk (M3), 
which are then both pasteurised and cooled. The skim milk is mixed with additives and is heated to $85{ }^{\circ} \mathrm{C}$ before it enters the evaporators (M10). The evaporation consists of an MVR and one triple effect thermal vapour recompression (TVR). The vapour is condensed and used to preheat incoming milk and air (components E1 and S2). The concentrate is heated again before it enters the spray dryer and fluidised bed. A detailed description of the system, state points and modelling approach can be found in [11].

The utility system consists of a natural gas boiler with an economiser for combustion air preheating. It supplies 25 bar saturated steam at $238{ }^{\circ} \mathrm{C}$. The cooling demand is covered by a brine referred to as ice water (IW) from an ammonia-refrigeration plant at $-5^{\circ} \mathrm{C}$. The plant has a production rate of 6.3 tons of milk powder per hour and operates during 7200 hours per year.

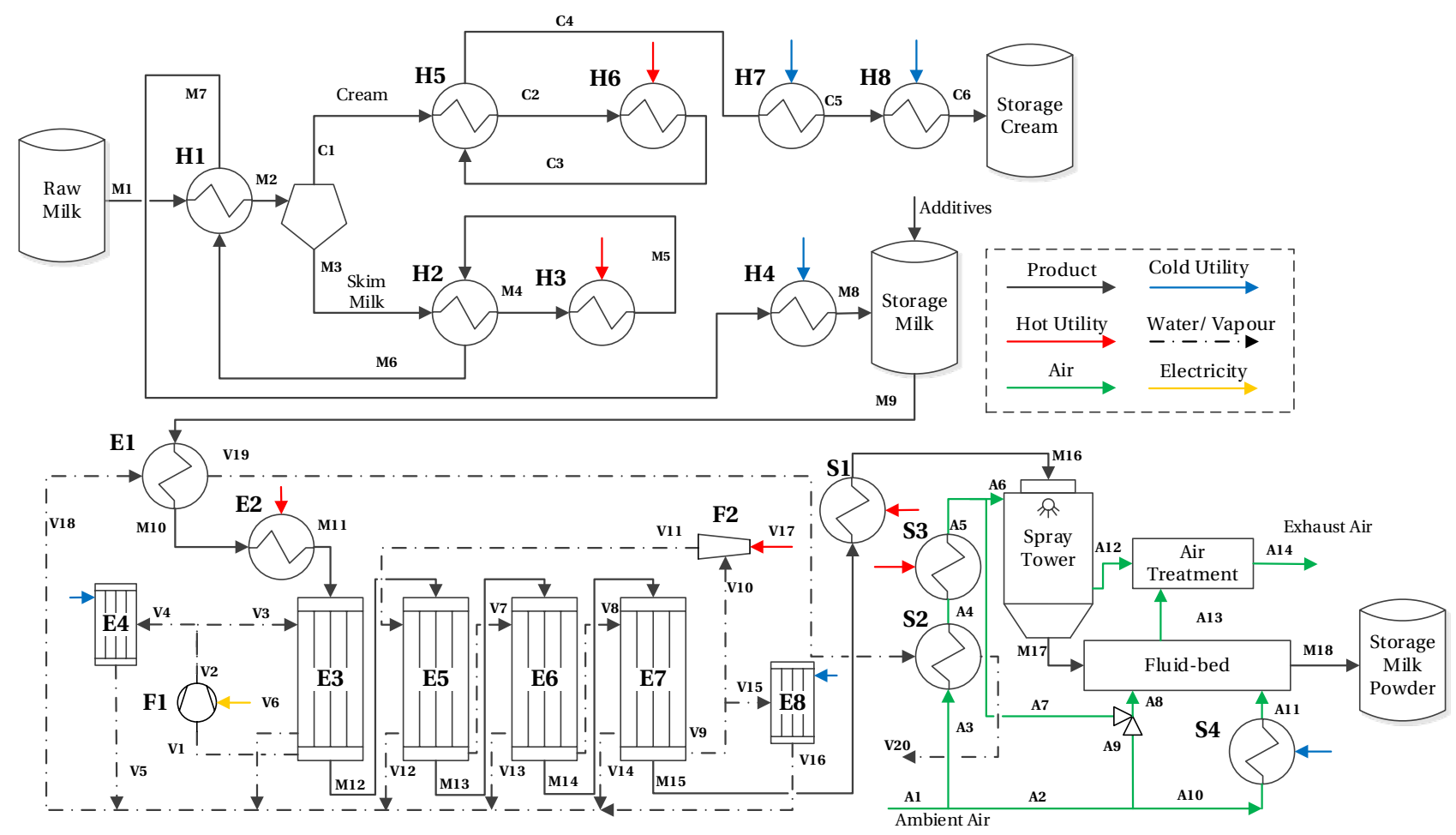

Figure 1. Dairy production system with the main products, utility streams and components (adopted in modified form from [11]). Components are named and numbered by H (milk treatment), E (evaporation) and S (drying). Process streams are named and numbered by M (milk), C (cream), V (vapour/ water) and A (air).

\subsection{Energy and exergy analysis}

The energy analysis of the model is based on the 1st Law of Thermodynamics. For an open system of constant volume, energy can be transferred in- and out of the system under study with streams of matter $\dot{H}$, heat $\dot{Q}$ and work $\dot{W}$. The present work does not consider changes in kinetic and potential energies, which implies that the energy balance in steady-state conditions, on a rate form, is as follows:

$$
\sum_{\text {in }} \dot{H}_{\text {in }}-\sum_{\text {out }} \dot{H}_{\text {out }}+\sum_{i} \dot{W}_{i}+\sum_{j} \dot{Q}_{j}=0
$$

Process integration techniques can be used for minimising the use of external utilities by maximising internal heat recovery within the system. The most well-known method is named 'pinch analysis' and was developed by Linnhoff and Hindmarsh [21] in the 80's for designing heat exchanger networks in chemical processes. It was also applied to industrial sites such as refineries, as discussed in Smith [22] and Klemeš [23], 
and it has been applied to dairy factories [24]. The pinch method calculates at first the heating and cooling demands with the corresponding temperatures and flows for each process stream. A minimum temperature difference is chosen, which sets the heat transfer driving force between two streams in a given heat exchanger. The system is then evaluated with respect to the maximum internal heat recovery and minimum utility demands (setting thermodynamic targets). Finally, system improvements by means of a re-design of the heat exchanger network (retrofit) or integration of processes, such as cogeneration and heat pumping, are suggested and the energy savings are estimated.

Unlike energy, exergy can be destroyed and accounts for the irreversibilities of the system. It can be defined as the maximum useful work delivered when the system is brought into complete thermodynamic equilibrium with its environment. A system in thermal and mechanical equilibrium (same temperature and pressure) with the environment is called 'restricted dead state' [25], while it is in 'dead state' if also in chemical equilibrium (same chemical species). In this work the environmental state was defined at $15{ }^{\circ} \mathrm{C}$ and 1 bar.

This thermodynamic concept builds on the First and Second Law of Thermodynamics, reflecting that all transformations are irreversible in nature and generate entropy. The exergy destruction $\dot{E}_{\mathrm{D}}$ is defined as the sum of all exergy streams associated with streams of matter $\dot{E}_{i}$, work $\dot{E}_{i}^{W}$ and heat $\dot{E}_{i}^{Q}$ that enter or leave the system under study, and can thus be derived from the previous relations as:

$$
\begin{gathered}
\sum_{i} \dot{E}_{i}+\sum_{i} \dot{E}_{i}^{W}+\sum_{i} \dot{E}_{i}^{Q}=\dot{E}_{\mathrm{D}} \\
\dot{E}_{l}=\dot{m}_{l}\left[\left(h_{i}-h_{0}\right)-T_{0}\left(s_{i}-s_{0}\right)\right]
\end{gathered}
$$

The exergy content of electricity is equal to its energy content. Exergy streams out of the system, without any utilization are referred to as exergy losses. The useful exergy is referred to as product, while the supplied valuable exergy is referred to as fuel.

\subsection{Electrification}

This paper focusses on electrification strategies for the retrofit of existing industrial plants. The evaluation of the electrification was performed for different electrification scenarios, which were based on strategies considering central and decentral electric utilities, as well as heat pumps and electric heaters. The overall approach for electrification followed these steps:

1. Modelling of the existing system and its utilities (Base scenario)

2. Pinch analysis, process optimisation and excess heat recovery

3. Technology evaluation for electric process alternatives according to different electrification scenarios

4. Modelling and analysis of electrification scenarios based on the proposed strategies

5. Comparison and evaluation of the scenarios

The retrofit electrification can take origin in the existing utility infrastructure, keeping a central generation of steam and ice water. This central utility can be based on boilers or centralised heat pumps. Alternatively, a decentralised utility can be implemented, providing the cooling and heating directly at the respective processes. Figure 2 shows these different electrification strategies, which were developed and evaluated for the case of the milk powder production. Figure 2 (a) shows utility and production of a factory in the base scenario, using natural gas as the primary energy source. In Figure 2 (b), the natural gas boiler is replaced by an electric one. The utility infrastructure is not modified, but process optimisation could be implemented in this scenario. The third case (Figure 2 (c)) has a central production of heating and cooling at different temperature levels which were selected based on the heating requirements. The utility is further integrated with the existing factory and utilises excess heat and natural heat sources. The last option, presented in Figure 2 (d), has a decentralised 
utility supply. Here individual options for each process are implemented, keeping the individual production units independent of each other. In this work, electric heating elements and heat pumps were considered as electrification technologies. Other possible alternative activators, such as microwave and infrared heating, were not considered. The existing plant considered in the case study had some opportunities for excess heat recovery [11], these were integrated into the electrified scenarios. Furthermore, the possibility to replace the TVR with a second MVR exists, which would increase energy efficiency but also fully electrify the evaporation. 


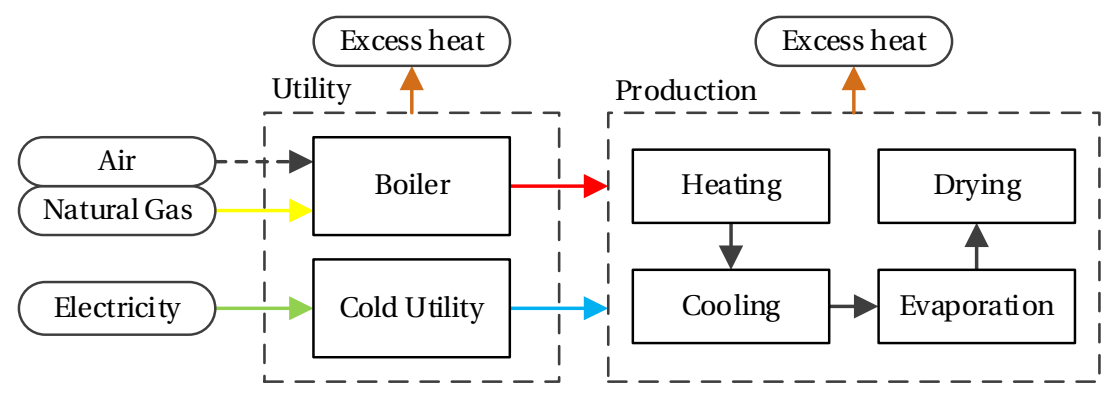

(a) Central Utility: Natural gas boiler and cooling unit

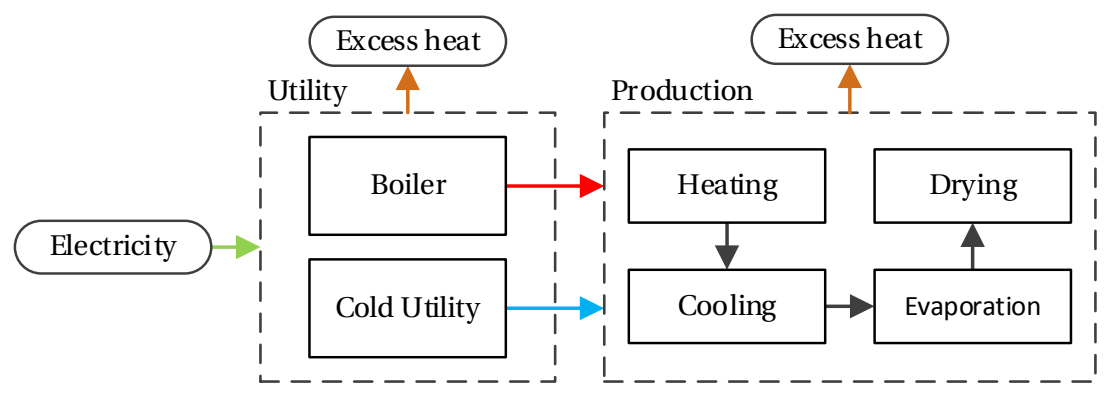

(b) Central Utility: Electric boiler and cooling unit

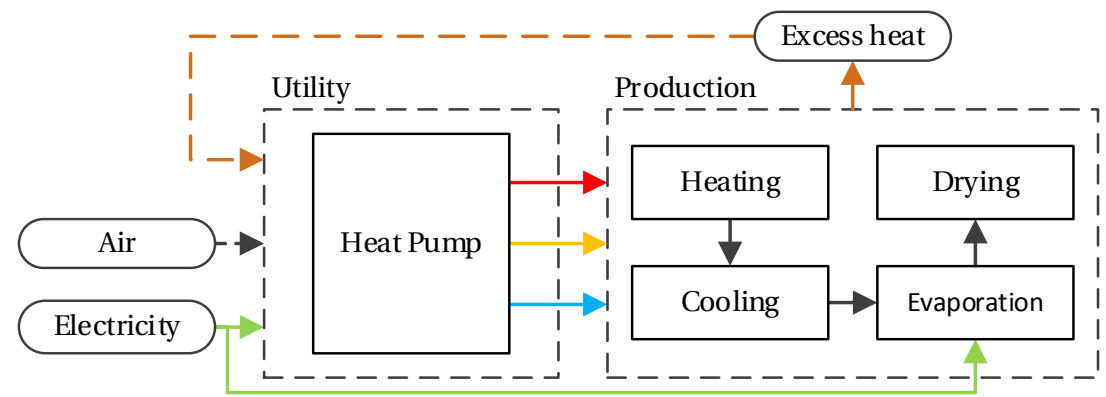

(c) Central integrated utility with heat pump system

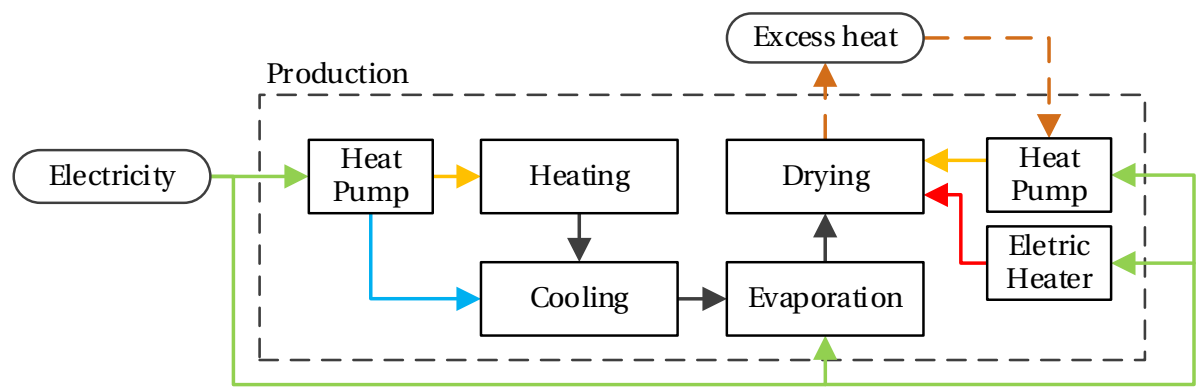

(d) Decentralised integrated utility with heat pumps and electric heaters

Figure 2. Base scenario (a) and electrification strategies (b - d) for a schematic dairy production system.

Based on the possible electrification strategies, four electrification scenarios were developed and compared to the current natural gas based scenario. The first two scenarios used the existing dairy system without any modifications to the existing processes and act as a reference for the proceeding analyses. 
- Base scenario 0 (Business as usual (BAU) - Utility: Central natural gas boiler \& cooling unit), corresponding to Figure 2 (a):

The process demands were satisfied using a central utility system providing steam and ice water. The central utility consisted of a natural gas boiler and a conventional electricity-driven ammonia refrigeration unit.

- Electrification scenario 1 (BAU - Utility: Central Electric boiler \& cooling unit), corresponding to Figure 2 (b):

The hot utility from Scenario 1 was replaced by a central electric boiler.

Opportunities for heat recovery and process electrification were included in the following scenarios. The introduced changes reduced the overall need for heating and cooling supply to the processes. The optimization of the processes, with respect to integration and waste heat recovery, was dependent on the chosen utility system, causing slight deviations in the utility consumption. The optimization was performed to minimize the final energy use of the factory and included the replacement of a TVR evaporator with MVR, the use of condensate cooling and exhaust drying air for direct preheating of the drying air intake.

- Electrification scenario 2 (Optimised processes - Utility: Central electric boiler \& cooling unit), corresponding to Figure 2 (b) with implementation of energy efficiency measures:

A central electric boiler was used to provide heating to the optimised dairy production system. The cooling was supplied by a conventional electricity-driven ammonia refrigeration unit.

- Electrification scenario 3 (Optimised processes - Utility: Central integrated heat pump system), corresponding to Figure 2 (c):

The heating and cooling was supplied by a central heat pump system, which collects all excess heat and cooling demands, to supply heat to the individual processes.

- Electrification scenario 4 (Optimised processes - Utility: Decentral integrated HPs \& Electric heater), corresponding to Figure 2 (d):

In this scenario the heating and cooling was supplied directly to the processes. There were no interconnections between the different parts of the production system to minimise interdependences. The solutions were further chosen to be implementable close to the production and to require a minimum of additional infrastructure, such as steam piping.

The five different scenarios were analysed with respect to their performance regarding energy, exergy, economy and environmental impact. Process integration was further used to analyse the systems in more detail.

\subsection{System modelling and assumptions}

\subsubsection{Dairy system}

A detailed description of the modelling approach of the dairy system is given in Bühler et al. [11]. Heat transfer equipment was modelled based on the streams inlet and outlet enthalpies and mass flow rates, while neglecting pressure loss. The thermal properties of dairy streams were found based on their composition with correlations by Singh and Heldman [26]. The ejector of the TVR was modelled based on its entrainment ratio [27] with a nozzle and diffuser efficiency of $92 \%$. The MVR was modelled using an isentropic compressor efficiency of $75 \%$. The spray dryer and fluidised bed dryers were modelled with a fixed air to product ratio, which was determined based on factory data [11]. The dryer exhaust air was modelled as humid air, considering the enthalpy of vaporization in the heat recovery scenarios.

\subsubsection{Central utility systems}

\section{Natural gas boiler:}

The hot utility in the BAU scenario was based on the combustion of natural gas which was approximated by a complete combustion of methane at an excess air ratio of 1.67 and combustion temperature of $1325{ }^{\circ} \mathrm{C}$. An economiser was used to preheat the air with the boiler flue gases. It was assumed to have a minimum 
temperature difference of $10 \mathrm{~K}$. No heat losses from the steam distribution network were considered. The cold utility in the BAU scenario was a simple vapour compression cycle with ammonia (R-717) as working fluid and a compressor isentropic efficiency of $75 \%$.

\section{Electric boiler:}

Electric heating elements and boilers were assumed to convert the electric energy input to the useful thermal energy at an efficiency of $100 \%$.

\section{Heat pump steam generation system:}

The central heat pump-based steam generation system consisted of bottom heat pump cycles, a central evaporator and a steam compression unit on top. The bottom cycles utilised different heat sources, such as excess heat from the processes or the ambient, and supplied heat to the evaporator at $90{ }^{\circ} \mathrm{C}$. The evaporator operated at sub-atmospheric pressure and the steam was compressed in multiple stages using centrifugal compressor [28]. The pressure ratios were chosen around 3.2 [29,30] and the inter-stage cooling was realised by liquid injection. The compressors were assumed to operate with an isentropic efficiency of $74 \%$, while the gear, the motor and the inverter were assumed to have an efficiency of $95 \%, 95 \%$ and $98 \%$, respectively [30]. The superheating at compressor inlet was assumed to be $10 \mathrm{~K}$. It was achieved by recirculating compressed gas in the first compression stage and by the controlled liquid injection at the higher stages. The compressed steam was used to preheat the drying air and the condensate was assumed to be returned at subcooled conditions. Liquid from the evaporator was subcooled for supplying heat to all heat sinks below $85^{\circ} \mathrm{C}$.

\subsubsection{Heat pumps}

The heat pumps considered in the different scenarios were electricity-driven vapour compression heat pumps. Their performance was determined by numerical models based on energy and mass balances as well as their thermodynamic properties. The model consisted of an evaporator and superheater at the heat source and a desuperheater, condenser and subcooler at the heat sink (Figure 3). The cycle included further a compressor with an isentropic compressor efficiency of $80 \%$ and a throttling valve. Energy and mass balances were included for each component. The working fluid is evaporated and superheated by the heat source at a low pressure and subsequently compressed. The working fluid with a higher pressure and temperature is then condensed and subcooled before undergoing an isenthalpic expansion process. The outlet of the throttling valve is the inlet to the evaporator. All heat transfer was assumed to take place at a constant pressure. A minimum temperature difference of $5 \mathrm{~K}$ was chosen for the heat exchangers. The outlet of the subcooler was set to $5 \mathrm{~K}$ above the sink inlet temperature. A minimum of $5 \mathrm{~K}$ superheating was considered and increased if required to ensure a dry compression at the outlet of the compressor. The coefficient of performance for heating $\left(\mathrm{COP}_{h}\right)$ can be found with Eq. (4), where the total useful heat rate is divided by the work input. The Lorenz efficiency, $\eta_{\text {Lor }}$, can be used to compare the performance of the actual heat pump to the theoretically possible COP, as shown in Eq. (5). The Lorenz COP was found by dividing the logarithmic mean temperature on the hot side of the heat pump, by the difference between the logarithmic mean temperatures of the hot and the cold side.

$$
\begin{gathered}
\mathrm{COP}_{h}=\frac{\dot{Q}_{h}}{\dot{W}} \\
\eta_{\text {Lor }}=\frac{\operatorname{COP}_{h}}{\operatorname{COP}_{\text {Lor }}}
\end{gathered}
$$

It was further assumed that product streams were not allowed to be in contact with the working fluid and thus intermediate water loops were used. Minimum temperature differences of $5 \mathrm{~K}$ for liquid/liquid, $7.5 \mathrm{~K}$ for 
liquid/gas and $10 \mathrm{~K}$ for gas/gas heat exchangers were applied. Pressure losses in the water loop were disregarded.
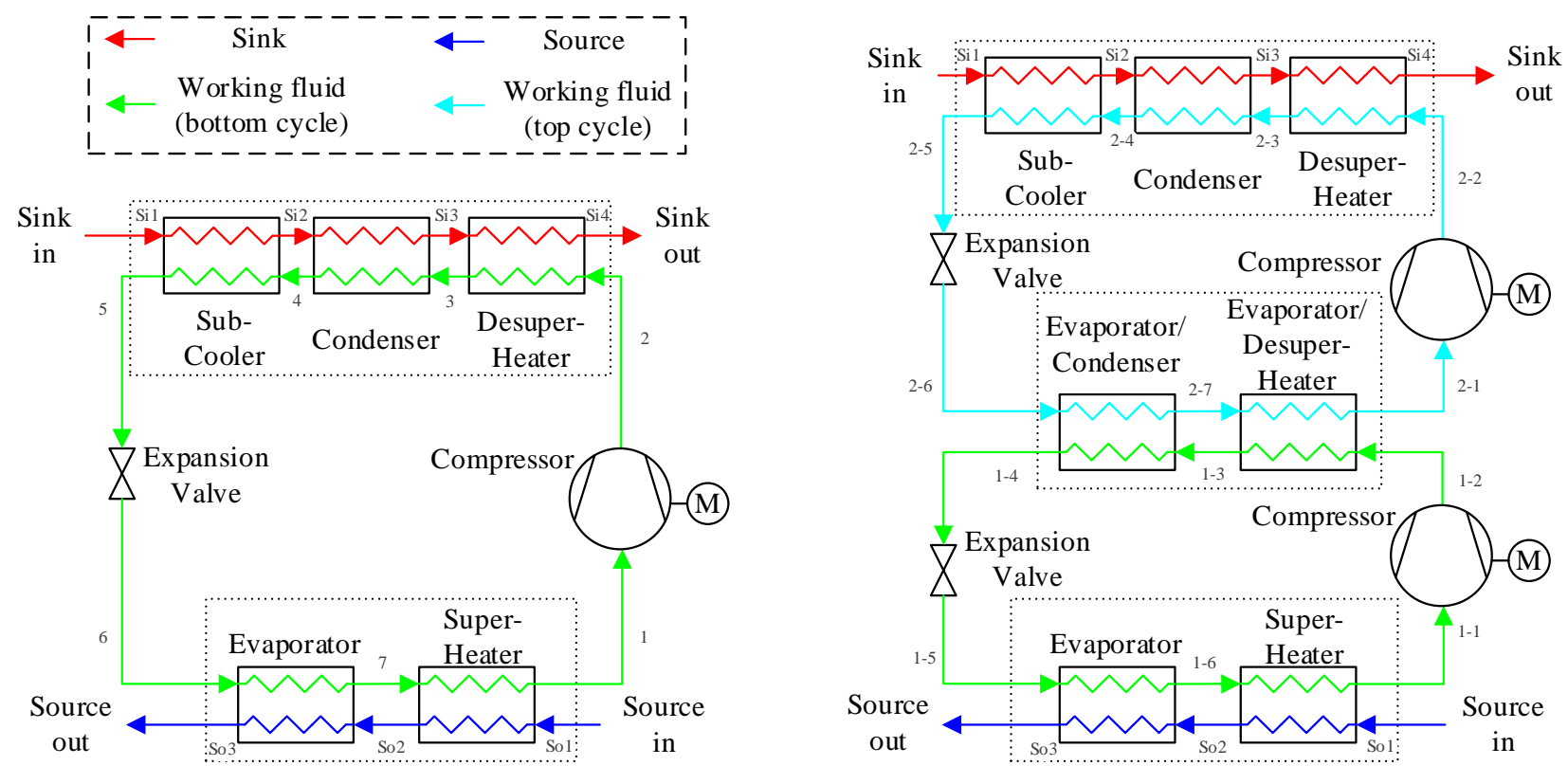

Figure 3: Layout of the single stage heat pump cycle (left) and cascade configuration (right) used for modelling.

The working fluids were chosen according to the temperature levels. For supply temperatures below $90{ }^{\circ} \mathrm{C}, \mathrm{R}-290$ (propane) was chosen as the working fluid. For higher temperatures, R-600 (butane) was selected [31]. If the temperature differences did not allow a single stage cycle, a cascade configuration was implemented using R-290 in the bottom and R-600 in the top cycle or a combination of R-600 and R-601a (iso-pentane) at higher temperatures.

\subsection{Economic evaluation}

In order to evaluate the economic performance of the different scenarios and solutions, the investment and operating costs were determined, based on a preliminary sizing and cost correlations for each equipment item.

\subsubsection{Component sizing}

The sizing of heat transfer equipment was done with a fixed overall heat transfer coefficient $U$, which was determined based on the fluids and equipment types. Using Eq. (6), the heat transfer area $A$ was found for a known heat flow rate and logarithmic mean temperature difference LMTD.

$$
\dot{Q}=U A \text { LMTD }
$$

The applied values for $U$ are shown in Table 4 in the Appendix and were selected based on recommendations by [32]. Condensers were further divided into their desuperheating, condensing and subcooling sections. Condensers, evaporators and liquid/liquid heat exchangers, were assumed to be plate heat exchangers. Large heat exchangers with liquid/gas or gas/gas were assumed to be of shell and tube type. The minimum approach temperatures were fixed with respect to the fluids in the heat exchangers. The values were based on $[33,34]$ who estimated them using the heat transfer film coefficient.

Compressors were sized based on their power or volume flow rate, depending on the cost correlations. Small compressors $(<500 \mathrm{~kW}$ ) were assumed to be screw compressors and larger ones were reciprocating or centrifugal compressors. The fast revolving high pressure fan for the MVR was dimensioned based on the 
required volume flow rate and the evaporator was based on overall heat transfer coefficients for falling film evaporation.

\subsubsection{Component cost estimation}

The estimation of the bare module costs was performed based on cost correlations found in the literature $[35,36]$ and information provided by suppliers. An overview of the used correlations is given in Table 5, for which the standard purchased equipment costs $C_{P}^{0}$ were found with the parameters $k$ and size parameter $x$, using Eq. (7).

$$
\log \left(C_{P}^{0}\right)=k_{1}+k_{2} \log (x)+k_{3}(\log (x))^{2}
$$

These standard purchased equipment costs were further corrected with pressure and material factors and were adjusted using the Chemical Engineering Plant Cost Index (CEPCI) for the year 2017. The obtained bare module costs, $C_{P}$, were multiplied with a factor of 1.18 to account for contingency and fees. As the new process equipment is a retrofit of the plant, an additional $15 \%$ of the total module capital costs were added to obtain the total capital investment costs (TCI) of the equipment.

Small compressors (below $100 \mathrm{~kW}$ ) were calculated based on cost functions by Ommen et al. [37], which were based on list prices. The function was fitted and a factor of 3.16, based on [36], was used to convert the purchased equipment costs to the bare module costs.

The investment costs for electric boilers were retrieved from [38], for which nominal investment costs for sizes of $1 \mathrm{MW}$ and higher were presented. It was assumed that a $10 \mathrm{kV}$ connection to the grid existed.

\subsubsection{Operation and maintenance costs}

The costs for natural gas and electricity were determined for Denmark for different years based on data from [39-41]. In addition energy prices were compiled for Germany based on [42] and data from Eurostat [43] were used for comparison with the EU28 average. In the Danish price scenarios, price forecasts were coupled with the expected Danish taxes for energy use in industrial processes and for the case of natural gas with $\mathrm{CO}_{2-}$ emission costs. Prices were assumed to be applicable to large industrial sites for process heating purposes. A detailed analysis of the prices and price forecasts is not in the scope of this study, it is however noteworthy that electricity prices from Eurostat are considerably higher for Germany and lower for Denmark. This is most probable due to that Eurostat does not fully reduce taxes for energy use in industrial processes. The analysis using different energy prices can therefore be seen as a sensitivity analysis. An overview of the price scenarios are shown in Table 6 in the Appendix. In all economic evaluations, a fixed energy price was used which was based on the year of the investment. Maintenance costs were further included as a one-time payment of $20 \%$ of the total capital investment costs [31]. As the maintenance costs of the existing system were not included, this represents additional expenses for maintenance of the electricity based systems.

\subsubsection{Economic evaluation}

The economic evaluation was based on several indicators to evaluate the feasibility and economic gain of investments in the different scenarios. The Net Present Value (NPV) was used as an indicator of the economic performance of the overall investments and to compare the solutions to each other. The NPV was found using Eq. (8) for a lifetime of $N=20$ years with a discount rate of $d=5 \%$.

$$
\mathrm{NPV}=\mathrm{TCI}+\sum_{n=1}^{N} \frac{\mathrm{CF}_{n}}{(1+d)^{t}}
$$


The annual net cash flows CF were obtained using Eq. (9) and adjusted for an annual inflation rate of $i=$ $2 \%$.

$$
\mathrm{CF}_{n}=\left[\left(c_{N G} \dot{Q}_{\mathrm{NG}} H+c_{\mathrm{El}} \dot{W}_{\mathrm{El}} H\right)_{\text {Base Scenario }}-c_{\mathrm{El}} \dot{Q}_{\mathrm{El}} H\right](1+i)^{n}
$$

The annual lifetime costs $C_{\mathrm{A}}$ of implementing the individual solutions were further investigated for Scenario 4 and calculated using Eq. (10) and Eq. (11) [25].

$$
\begin{aligned}
& C_{A}=\mathrm{CRF} \cdot \mathrm{TCI}+\frac{1}{N} \sum_{n=1}^{N} \mathrm{CF}_{n} \\
& \mathrm{CRF}=\frac{i_{\text {eff }}\left(1+i_{\mathrm{eff}}\right)^{N}}{\left(1+i_{\mathrm{eff}}\right)^{N}-1} \text {, with } i_{\text {eff }}=\frac{1+d}{1+i}-1
\end{aligned}
$$

This was used to visualise the individual options of Scenario 5 in marginal cost curves [44]. Marginal cost curves in this work represent the specific annual costs for implementing a measure and their contribution to the total electrification potential. Negative costs imply specific savings, while positive values can be interpreted as additional costs imposed due to the implementation of a given measure.

\subsection{Environmental evaluation}

An environmental evaluation of the different solutions was performed to assess the change in $\mathrm{CO}_{2}$ emissions from the factory for the different solutions and under different emission frameworks. The comparison was based on the EU Reference Scenario 2016 [40], where long term energy trends until 2050 are projected for all EU member states. To show regional and temporal differences in $\mathrm{CO}_{2}$-emission, the comparison was done for Denmark and the average EU-28 for the years 2015, 2025 and 2050. An additional analysis was done for Denmark for the year 2015 (DK-CHP), where the $\mathrm{CO}_{2}$-emissions for electricity were allocated between heat and power production in combined heat and power plants (CHP) based on the $125 \%$ method [41]. This method assumes a heating efficiency of $125 \%$, which is used to find the fuel use for heat production in CHP plants. By using this method specific $\mathrm{CO}_{2}$-emissions for electricity of 0.23 tons per MWh are found, compared to 0.17 tons per MWh for equal distribution between heat and power. The emissions in the EU reference scenario refer to the production of heat and power. For the EU-28 the specific emissions are expected to decrease from 0.30 tons per MWh in 2016 to 0.08 tons per MWh in 2050.

\section{Results}

In this section first detailed results of each scenario are presented, followed by the energy, exergy and environmental analyses. At the end the economic evaluation of the electrification scenarios is presented.

\subsection{Scenarios}

For each scenario a detailed analysis is presented in the following subsections. The results include the overall energy balance for the overall system and the main components.

\subsubsection{Base scenario 0 (BAU - Utility: Central natural gas boiler \& cooling unit)}

Table 1 summarises the streams of the baseline scenario. Based on process integration techniques, the grand composite curve of the baseline configuration, without any modification to the existing system, is shown in Figure 4. Considering only the process heating and cooling demands, the minimum hot utility (HU) demand, excluding the evaporators, is $11.33 \mathrm{MW}$ and the minimum cold utility (CU) demand is $235 \mathrm{~kW}$. These minimum energy requirements are very close to the actual demands at the factory, which were $11.42 \mathrm{MW}$ for heating and $374 \mathrm{~kW}$ for cooling. To reach the target value the cooling of cream in the cooler $\mathrm{H7}$ could be used 
for pre-heating the drying air after the regenerative heater S2. There are also two streams with excess heat (EH1 and EH2 in Table 1) rejected to the environment. Including those as free streams, i.e. streams which residual heat can be used, the utility heating demand could be reduced to $8.73 \mathrm{MW}$ assuming a final temperature of $15^{\circ} \mathrm{C}$ of those streams. This reduction is primarily from the exhaust drying air (EH1) at point A14 which could be used for direct integration. The condensate (EH2) at point V20 after preheating the drying air would require a heat pump. Figure 4 also shows process streams including the evaporators. The evaporation in the MVR takes place at $75^{\circ} \mathrm{C}$, while in the triple effect TVR evaporator the evaporation occurs at $67^{\circ} \mathrm{C}$, $58{ }^{\circ} \mathrm{C}$ and $52{ }^{\circ} \mathrm{C}$ respectively. The MVR increases the dry matter content from $15 \%$ to $35 \%$ and after the TVR it reaches the required $52 \%$. A detailed analysis of the evaporation section is presented in [11]. The TVR uses just below $1 \mathrm{MW}$ of fresh steam, while the compressor in the MVR requires $280 \mathrm{~kW}$. The real natural consumption for heating purposes reaches $14.37 \mathrm{MW}$ based on the higher heating value and the iced water production for cooling requires $252.5 \mathrm{~kW}$ of electric power.

Table 1. Stream table of the heating and cooling demands of the baseline configuration (Scenario 0).

\begin{tabular}{cccrrrrrrr}
\hline Component & $\begin{array}{c}\text { State } \\
\text { Point In }\end{array}$ & $\begin{array}{c}\text { State } \\
\text { Point Out }\end{array}$ & $\begin{array}{c}T_{\mathrm{S}} \\
{\left[{ }^{\circ} \mathrm{C}\right]}\end{array}$ & $\begin{array}{c}T_{\mathrm{T}} \\
{\left[{ }^{\circ} \mathrm{C}\right]}\end{array}$ & $\begin{array}{c}c_{\mathrm{p}} \\
{[\mathrm{kJ} /(\mathrm{kg} \mathrm{K})]}\end{array}$ & $\begin{array}{c}h_{\text {in }} \\
{[\mathrm{kJ} / \mathrm{kg}]}\end{array}$ & $\begin{array}{c}h_{\text {out }} \\
{[\mathrm{kJ} / \mathrm{kg}]}\end{array}$ & $\begin{array}{c}\dot{m} \\
{[\mathrm{~kg} / \mathrm{s}]}\end{array}$ & $\begin{array}{c}\dot{Q} \\
{[\mathrm{~kW}]}\end{array}$ \\
\hline H3 & M4 & M5 & 70 & 75 & 3.97 & & & 10.7 & 212 \\
H6 & C2 & C3 & 77 & 85 & 3.33 & & & 1.2 & 32 \\
E2 & M10 & M11 & 75 & 85 & 3.84 & & & 11.4 & 453 \\
S1 & M15 & M16 & 52 & 75 & 2.94 & & & 3.3 & 222 \\
S3 & A4 & A5 & 23 & 210 & & 39.8 & 231.2 & 54.9 & 10501 \\
H4 & M7 & M8 & 8.1 & 5 & 3.94 & & & 10.7 & 128 \\
H7 & C4 & C5 & 58 & 23 & 3.30 & & & 1.2 & 138 \\
H8 & C5 & C6 & 23 & 5 & 3.29 & & & 1.2 & 70 \\
S4 & A10 & A11 & 15 & 8 & & 31.3 & 24.2 & 5.4 & 39 \\
EH1 & A14 & & 74 & 30 & & 149.6 & 104.0 & 64.3 & 2930 \\
EH2 & V20 & & 25 & 15 & & 166.3 & 63.1 & 8.3 & 854 \\
\hline
\end{tabular}




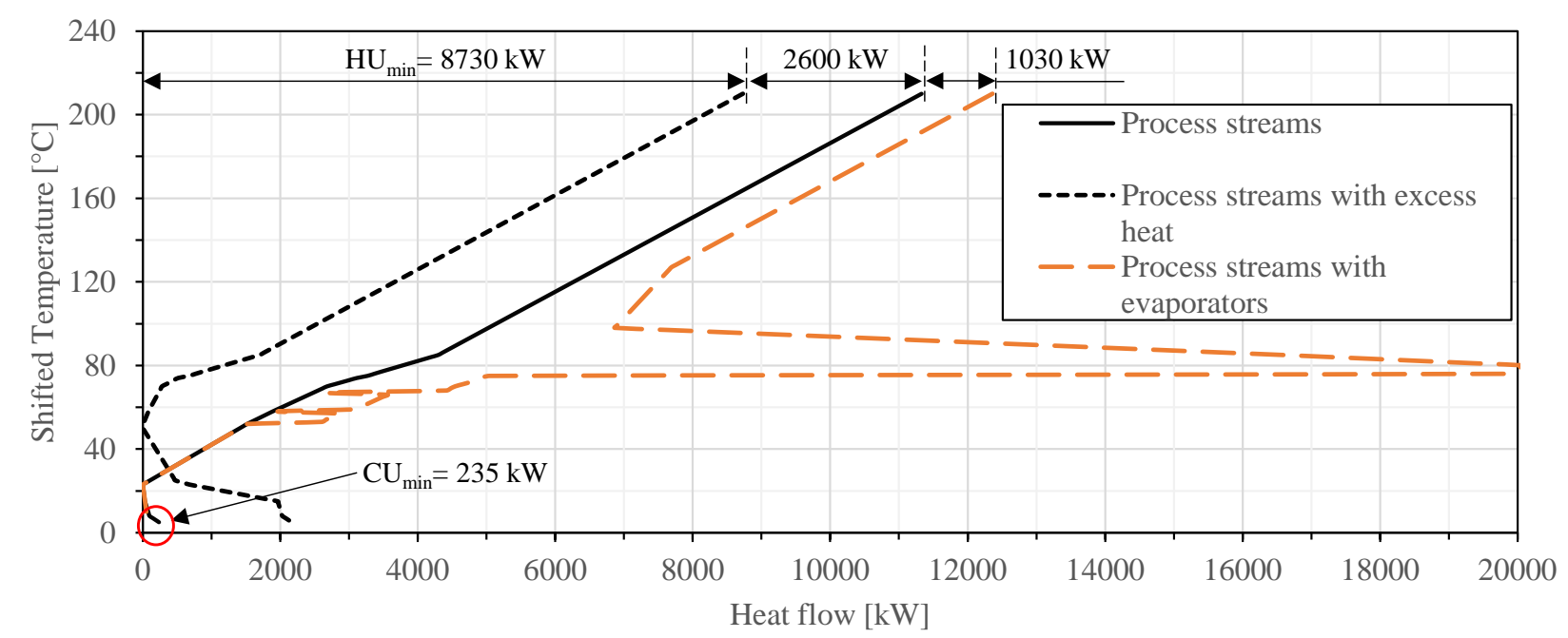

Figure 4: Grand composite curves of the current dairy system including only process streams (black line), process stream with excess heat sources (dashed black line) and process streams including the evaporators (dashed orange line).

\subsubsection{Electrification Scenario 1 (BAU - Utility: Central electric boiler \& cooling unit)}

In the electrification scenario 1, the natural gas boiler was replaced with an electric boiler, while the remaining processes stayed unchanged. The stream table and grand composite curve (GCC) is unchanged, as the only modifications concern the utility system. The steam for the hot utility is generated in an electric boiler with a thermal efficiency of $100 \%$.

\subsubsection{Electrification Scenario 2 (Optimised processes - Utility: Central Electric boiler \& cooling unit)}

Replacing the TVR with an additional MVR had a great impact on the system. The energy use per kilogram of evaporated water was considerably lowered compared to a TVR system $[8,45]$. Furthermore, the amount and temperature of condensate was reduced as no steam was required, thus decreasing the preheating demand in E1. The reduction of condensate was primarily a result of the steam added to the ejector and the residual vapour from the second and third effect of the TVR. However, by modifying the system, it was possible to recover the heat from the two condensers which could then be utilised. The optimised system layout is shown in Figure 5. In the optimised process scenario, the total heating demand was reduced to 9.61 MW and the cooling demand to $237 \mathrm{~kW}$. The total electric energy input to the factory was $10.1 \mathrm{MW}$ out of which 357 $\mathrm{kW}$ was required for the two MVR evaporators. The excess heat of the system was 6.38 MW out of which 6.094 MW originated from the drying air.

The exhaust drying air could be used directly to preheat the incoming air before point A4. Assuming a minimum temperature difference of $10 \mathrm{~K}$ for an air-to-air heat exchanger, the drying air could be preheated to $64.2^{\circ} \mathrm{C}$. This would leave the exhaust air at $39.3^{\circ} \mathrm{C}$ which could be utilised with a heat pump. 


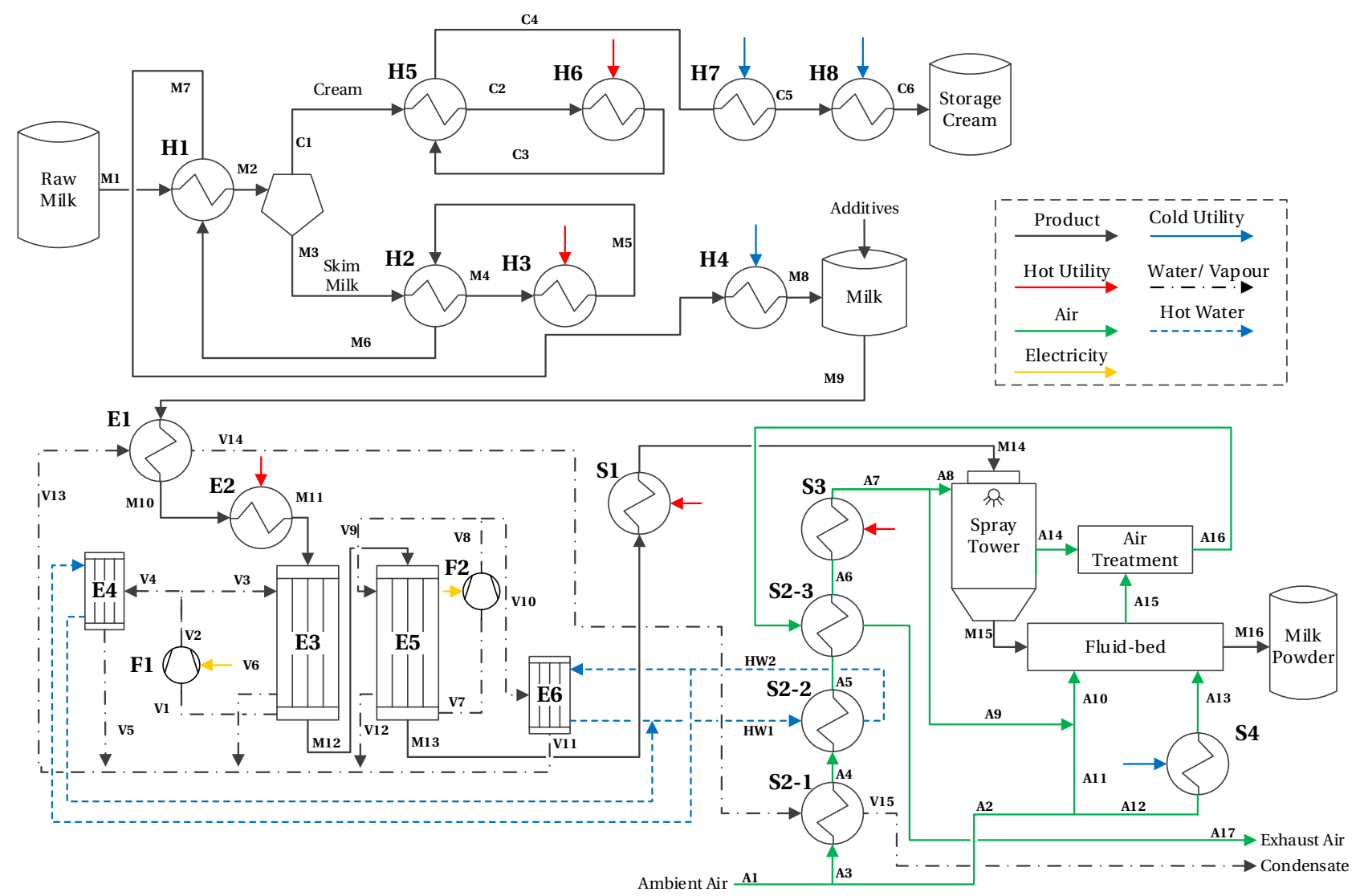

Figure 5: Layout of the optimised dairy production system with the addition of an MVR evaporator and integration of the exhaust drying air and condensate cooling (Scenario 2)

\subsubsection{Electrification Scenario 3 (Optimised processes - Utility: Central integrated heat pump system}

In order to supply the heating and cooling more efficiently, an integrated hot and cold utility, as well as the utilization of the excess heat streams was taken into account in the electrification scenario 3 . The heating demand can be divided into two temperature levels, namely processes requiring heat up to $85{ }^{\circ} \mathrm{C}$ and the drying air which requires heating up to $210^{\circ} \mathrm{C}$. The existing ice water distribution could be kept, as the hot streams require cooling to target temperatures between $5^{\circ} \mathrm{C}$ and $8{ }^{\circ} \mathrm{C}$ with small temperature drops. These target temperatures are close to the current ice water temperatures.

Figure 6 shows the schematic layout of the central utility. The central part of the system is the evaporator, which provides both hot water for direct heat supply below $85{ }^{\circ} \mathrm{C}$ and steam for the steam compression system. The heat to the evaporator is supplied by six heat pumps (B-HP) which have a condensation temperature of $90^{\circ} \mathrm{C}$. The first heat pump generates the ice water for process cooling and the second cold water for cream cooling. Heat pump 3 uses the excess heat in the condensate after preheating the drying air (State V15) at a temperature of $20^{\circ} \mathrm{C}$. The fourth and the fifth heat pump recover the heat from the drying air (State A17), where heat pump 4 cools the drying air until the dew point (DP) and heat pump 5 until $21^{\circ} \mathrm{C}$. The last heat pump is a heat pump using ambient air and supplies the remaining required heat. An overview of the individual heat pumps can be found in Table 2. The hot water distribution to Sink 1 to 4 and S 3-1 could be designed as a hot water loop. 


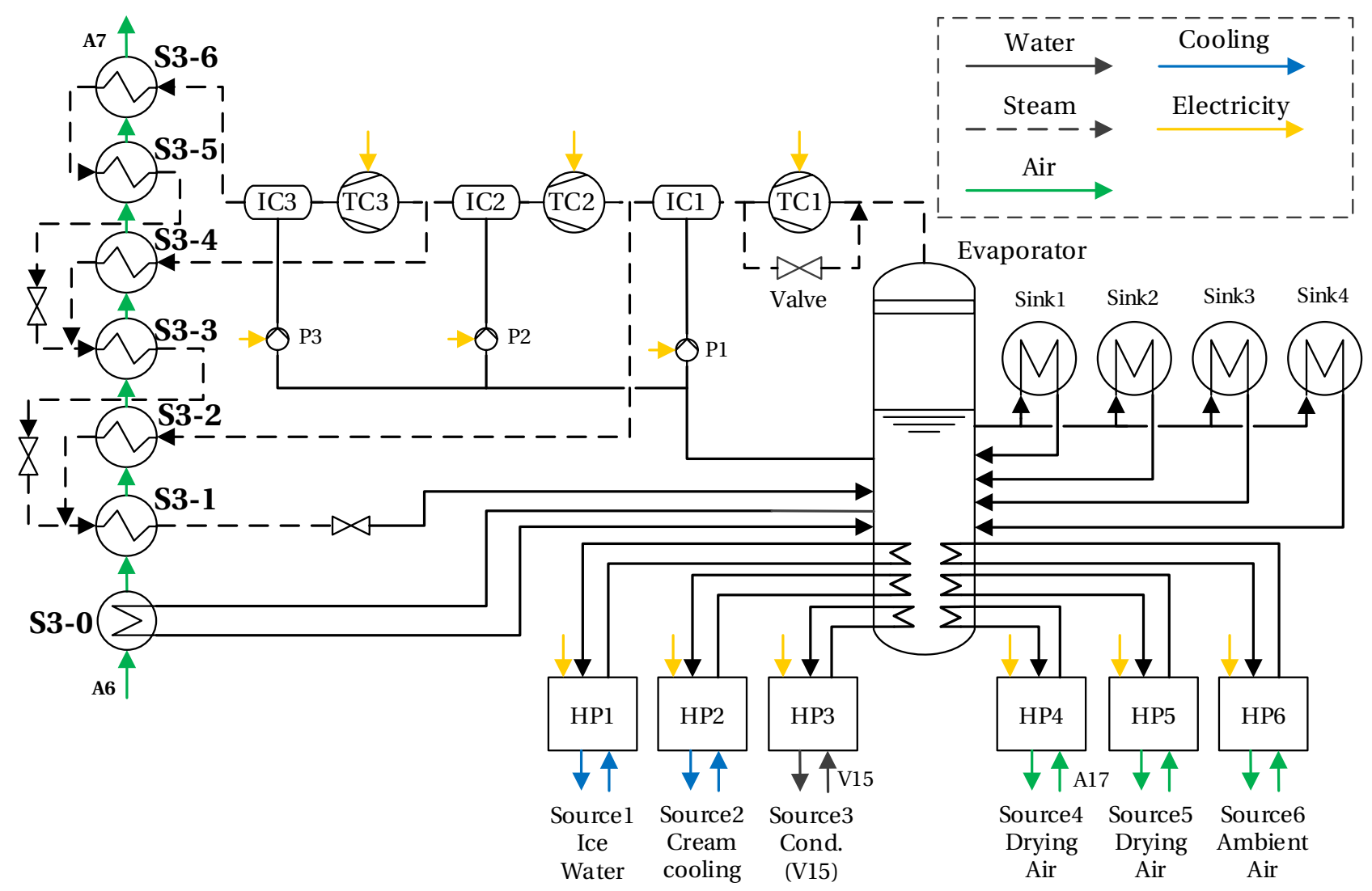

Figure 6: Central heat pump system as used in Scenario 3.The bottom heat pumps (HP1 to HP6) supply heat to the central evaporator, from where heat is delivered directly to processes (Sink 1 to Sink 4 and S3-0). From the evaporator a multi-stage cycle delivers steam to the air heating of the dryer.

Table 2: Overview of the central utility in the optimised process (Scenario 3). Bottom and top heat pumps refer to Figure 6 and the source properties to Figure 5.

\begin{tabular}{|c|c|c|c|c|c|c|c|c|c|}
\hline HP & Source & $T_{\text {Source }}$ & $T_{\text {Sink }}$ & НР Туре & $\begin{array}{c}\eta_{\text {Lor }} \\
{[-]}\end{array}$ & $\begin{array}{c}\dot{Q}_{\mathrm{h}} \\
{[\mathrm{kW}]}\end{array}$ & $\begin{array}{c}\dot{Q}_{\mathrm{c}} \\
{[\mathrm{kW}]}\end{array}$ & $\begin{array}{c}\dot{W} \\
{[\mathrm{~kW}]}\end{array}$ & $\begin{array}{c}\mathrm{COP}_{\mathrm{h}} \\
{[-]}\end{array}$ \\
\hline B-HP1 & IW & $4.9^{\circ} \mathrm{C} \rightarrow-2.5^{\circ} \mathrm{C}$ & $90^{\circ} \mathrm{C}$ & R290/ R600 & 0.57 & 417 & 238 & 179 & 2.3 \\
\hline B-HP2 & H7 & $25^{\circ} \mathrm{C} \rightarrow 15^{\circ} \mathrm{C}$ & $90^{\circ} \mathrm{C}$ & $\mathrm{R} 600$ & 0.48 & 230 & 138 & 92 & 2.5 \\
\hline В-HP3 & V15 & $20^{\circ} \mathrm{C} \rightarrow 15^{\circ} \mathrm{C}$ & $90^{\circ} \mathrm{C}$ & R600 & 0.47 & 425 & - & 177 & 2.4 \\
\hline B-HP4 & A17 & $50^{\circ} \mathrm{C} \rightarrow 31^{\circ} \mathrm{C}$ & $90^{\circ} \mathrm{C}$ & $\mathrm{R} 600$ & 0.44 & 1897 & - & 596 & 3.2 \\
\hline B-HP5 & A17 (DP) & $31^{\circ} \mathrm{C} \rightarrow 21^{\circ} \mathrm{C}$ & $90^{\circ} \mathrm{C}$ & R600 & 0.48 & 4330 & - & 1602 & 2.7 \\
\hline B-HP6 & Ambient & $15^{\circ} \mathrm{C}$ & $90{ }^{\circ} \mathrm{C}$ & R290/ R600 & 0.56 & 435 & - & 167 & 2.6 \\
\hline T-HP7 & Evap. & $90^{\circ} \mathrm{C}$ & $80^{\circ} \mathrm{C} \rightarrow 210^{\circ} \mathrm{C}$ & Water & 0.43 & 7335 & - & 2117 & 3.5 \\
\hline Total & - & - & - & - & - & 9608* & 375 & 4931 & 1.95 \\
\hline
\end{tabular}

${ }^{*}$ The total heat supply is less than the sum of each heat pump, as some of the heat from the B-HP is the source of the T-HP 


\subsubsection{Electrification Scenario 4 (Optimised processes - Utility: Decentral integrated HPs \& Electric heater)}

Electrification of the individual processes takes advantage of the possibility to supply the heating and cooling demands directly where they are needed. This eliminates the need for a central utility system and there is higher degree of flexibility possible as the production systems are independent of each other. The electrification can furthermore be conducted stepwise, as the investments in this scenario are independent of each other. The factory with decentral utilities is shown in Figure 7.

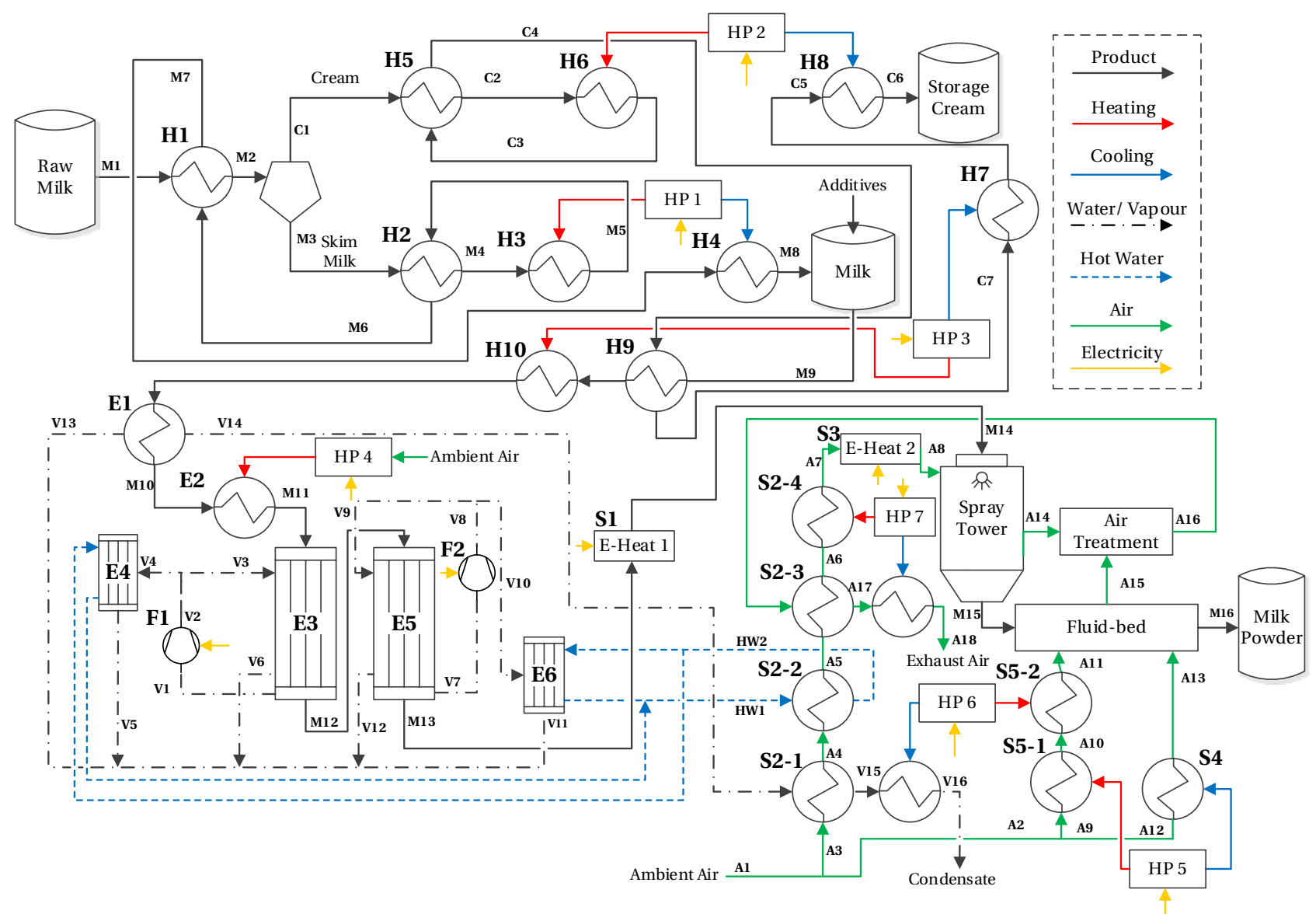

Figure 7: Dairy production system with optimised processes and decentral integrated utilities. The placement of the heat pumps and electric heaters is indicated.

In total seven heat pumps were integrated in the factory to supply heating and cooling to the processes and to utilise the excess heat. The placement of the heat pumps followed the strategy to not create major interdependencies between the production sections. Where possible, heat pumps were placed between the heaters and coolers of similar streams to supply heating and cooling from the same system. This was the case for milk and cream pasteurization and the air for the fluidised bed. The hot air to the spray dryer was covered by heat pumping the exhaust drying air after preheating. The heating of milk before the evaporator was done with a heat pump using ambient air. Electric heaters were used to boost temperatures when no other heat sources were available at sufficient temperatures. This was the case for the drying air where existing technologies can be economically used up to $140{ }^{\circ} \mathrm{C}$ [4]. The preheating of milk concentrate before the spray dryer, could be done by a heat pump using the remaining heat of the condensate at state V18. However, heat 
exchanger S1 is a Scraped Surface Heat Exchanger for the concentrated milk. In many dairies this is already electrically heated and it has a small heating demand compared to other units.

Table 3. Overview of the individual decentral utilities in the optimised process (Scenario 4). For each utility the source and sink properties are shown, with state points referring to Figure 7, as well as the thermodynamic performance.

\begin{tabular}{|c|c|c|c|c|c|c|c|c|c|c|}
\hline HP & $\begin{array}{l}\text { Source } \\
\text { Inlet }\end{array}$ & $\mathrm{T}_{\text {Source }}$ & $\begin{array}{l}\text { Sink } \\
\text { Inlet }\end{array}$ & $\mathrm{T}_{\text {Sink }}$ & HP Туре & $\begin{array}{c}\eta_{\text {Lor }} \\
{[-]}\end{array}$ & $\begin{array}{c}\dot{Q}_{\mathrm{h}} \\
{[\mathrm{kW}]}\end{array}$ & $\begin{array}{c}\dot{Q}_{\mathrm{c}} \\
{[\mathrm{kW}]}\end{array}$ & $\begin{array}{c}\dot{W} \\
{[\mathrm{~kW}]}\end{array}$ & $\begin{array}{c}\mathrm{COP}_{\mathrm{h}} \\
{[-]}\end{array}$ \\
\hline HP1 & M7 & $8^{\circ} \mathrm{C} \rightarrow 5.5^{\circ} \mathrm{C}$ & M4 & $70^{\circ} \mathrm{C} \rightarrow 75^{\circ} \mathrm{C}$ & R290 & 0.44 & 212 & 109 & 103 & 2.1 \\
\hline HP2 & C5 & $8^{\circ} \mathrm{C} \rightarrow 5^{\circ} \mathrm{C}$ & C2 & $77^{\circ} \mathrm{C} \rightarrow 85^{\circ} \mathrm{C}$ & R290 & 0.38 & 32 & 12 & 20 & 1.6 \\
\hline HP3 & C7 & $30^{\circ} \mathrm{C} \rightarrow 8^{\circ} \mathrm{C}$ & M9 & $27.5^{\circ} \mathrm{C} \rightarrow 30^{\circ} \mathrm{C}$ & R290 & 0.34 & 106 & 86 & 20 & 5.2 \\
\hline HP4 & Ambient & Ambient & M10 & $61.5^{\circ} \mathrm{C} \rightarrow 85^{\circ} \mathrm{C}$ & R290/ R600 & 0.52 & 1026 & - & 368 & 2.8 \\
\hline HP5 & A12 & $15^{\circ} \mathrm{C} \rightarrow 8^{\circ} \mathrm{C}$ & A9 & $15^{\circ} \mathrm{C} \rightarrow 30.9^{\circ} \mathrm{C}$ & R290 & 0.40 & 49 & 39 & 11 & 4.6 \\
\hline HP6 & V15 & $22.5^{\circ} \mathrm{C} \rightarrow 20.8^{\circ} \mathrm{C}$ & A10 & $30.9^{\circ} \mathrm{C} \rightarrow 55^{\circ} \mathrm{C}$ & R290 & 0.35 & 75 & - & 19 & 4.0 \\
\hline HP7 & A17 & $53.2^{\circ} \mathrm{C} \rightarrow 27.8^{\circ} \mathrm{C}$ & A6 & $64.3^{\circ} \mathrm{C} \rightarrow 140^{\circ} \mathrm{C}$ & R600/ R601a & 0.51 & 4197 & - & 1656 & 2.5 \\
\hline E-H 1 & - & - & M13 & $67^{\circ} \mathrm{C} \rightarrow 75^{\circ} \mathrm{C}$ & - & - & 77 & - & 77 & 1.0 \\
\hline E-H 2 & - & - & A7 & $140^{\circ} \mathrm{C} \rightarrow 210^{\circ} \mathrm{C}$ & - & - & 3919 & - & 3919 & 1.0 \\
\hline Total & - & - & & - & - & - & 9694 & 245 & 6194 & 1.57 \\
\hline
\end{tabular}

\subsection{Energy analysis}

The results of the energy analysis and comparison of the different scenarios are shown in Figure 8 and Figure 9. The throughput of raw milk and the production of cream and milk powder are constant in all the scenarios. The energy input in the base scenario 0 is reduced towards electrification scenario 1 through electrification by the heat losses in the boiler flue gases at a constant heating and cooling demand. When performing process optimisation and waste heat recovery, through replacement of the TVR with a second MVR evaporator, lower minimum temperature differences and increased heat recovery, the electricity input can be reduced by more than one fifth in scenario 2 compared to scenario 1 . However, the theoretical heat demand for the evaporator, which was 17.67 MW in base scenario 0 and electrification scenario 1 , was slightly increased to $17.83 \mathrm{MW}$. This is due to the evaporation at a higher temperature in the second MVR, compared to the previously used triple effect TVR where more flashing of water was present. 


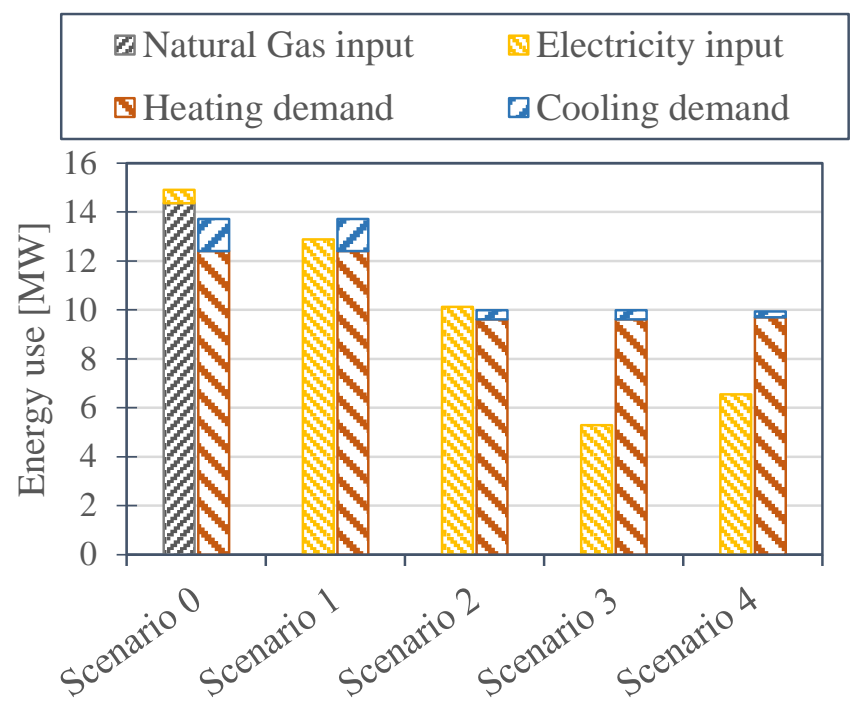

Figure 8: Overview of the total energy input and demand of the dairy factory under different scenarios.

By integrating heat pumps, the electricity use and the heat losses can be further reduced. The highest efficiency was obtained in scenario 3 where almost all available excess heat from the processes was used. Solely the drying air leaves B-HP 5 at $21^{\circ} \mathrm{C}$. In scenario 4, more heat losses were present as only the heating demand up to $140^{\circ} \mathrm{C}$ was covered by heat pumps and thus part of sensible and latent heat in the drying exhaust air was not utilised. Compared to the electrification scenario 2 , the electricity input was reduced by $48 \%$ using a central heat pump system and by $35 \%$ using the decentral heat pumps. The decrease in efficiency from scenario 3 to scenario 4 was caused by the design choices, namely the use of electric heaters for heating the drying air above $140{ }^{\circ} \mathrm{C}$. Implementing a heat pump to lift the temperature to the final one of the air would result in a low COP as the solution is not integrated. As shown by Zühlsdorf et al. [46] a high temperature heat pump for the spray dryer would yield a COP between 1.6 and 1.9. In this analysis a COP including the electric heater of 1.5 was obtained at considerably lower investment costs.

The specific energy use for milk powder could be reduced from 2.42 MWh per ton of powder in the base scenario to between 0.86 MWh and 1.06 MWh per ton of powder in Scenario 3 and 4 respectively.

While Figure 9 shows the energy content of the heat losses, it does not consider the temperature at which those occur. The utilisation potential of the excess heat from the ice water production are, for example, small as this heat source is near ambient conditions. On the other hand, the drying air and flue gases have a higher temperature and contain latent heat from water vapour. 


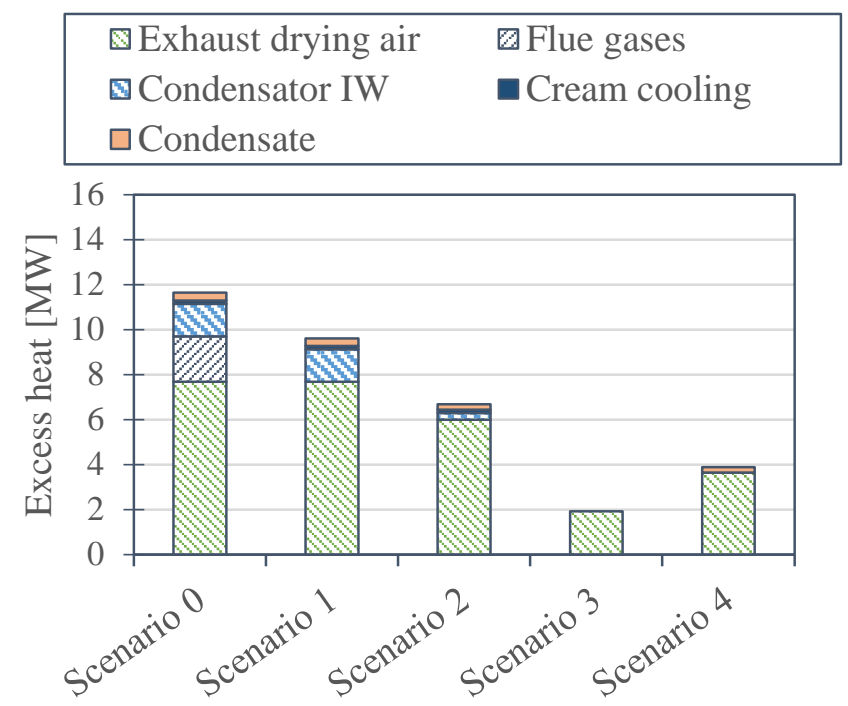

Figure 9: Overview of the excess heat of the dairy factory by source for the different electrification scenarios.

\subsection{Exergy analysis}

The results of the exergy analysis are shown in Figure 10 where the exergy flows for each scenario are represented in Grassmann diagrams. The highest source of exergy destruction in scenario 1 is the natural gas boiler, which also causes exergy losses of $453 \mathrm{~kW}$ in the form of flue gases. The remaining losses and destruction occur in the cold utility. The recirculation from the production to the utility is solely condensate and ice water. The main source of exergy destruction in the production is the spray dryer. By electrifying the utility in scenario 2, the exergy input is reduced by $15 \%$, while the exergy destruction in the utility is reduced by $20 \%$. The comparably low reduction indicates that there is still a mismatch between the utility and the actual process heating demand. The energy efficiency measures (scenario 3) reduce the exergy input by $39 \%$ and exergy destruction of the total factory by $30 \%$ compared to scenario 1 . Exergy losses are further minimised compared to the two previous scenarios.

Introducing a central heat pump system (scenario 4) considerably reduced the exergy input to the system (half compared to Scenario 3). The decentral solution (scenario 5) requires 1.26 MW more exergy input than scenario 4, and has a higher exergy destruction. In both cases the exergy losses are reduced considerably, where scenario 4 re-uses all losses, except for some drying exhaust air. 
(a) Exergy analysis of the base scenario 0 (BAU)

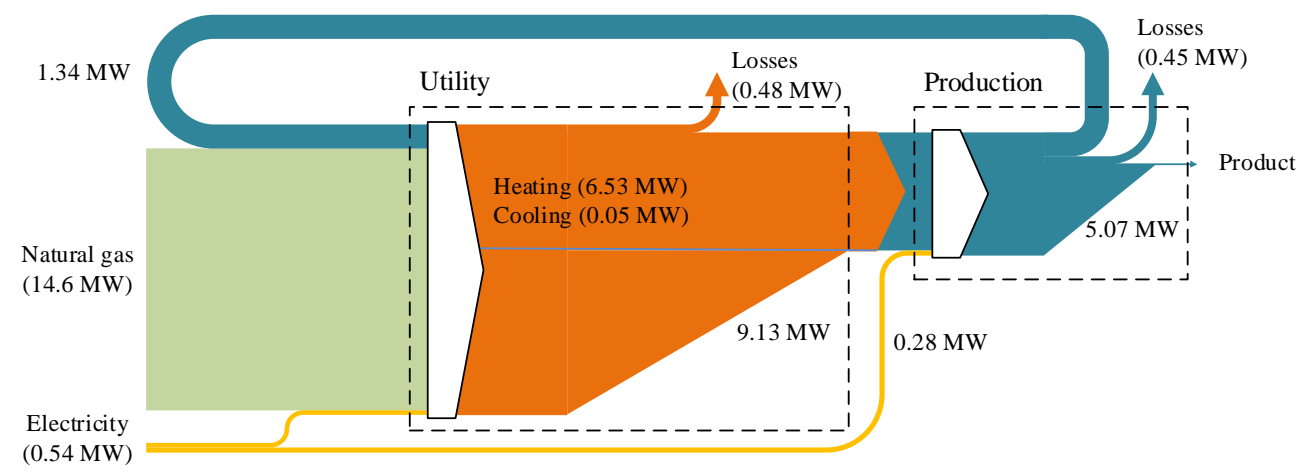

(b) Exergy analysis of electrification scenario 1 (BAU-Electric Utility)

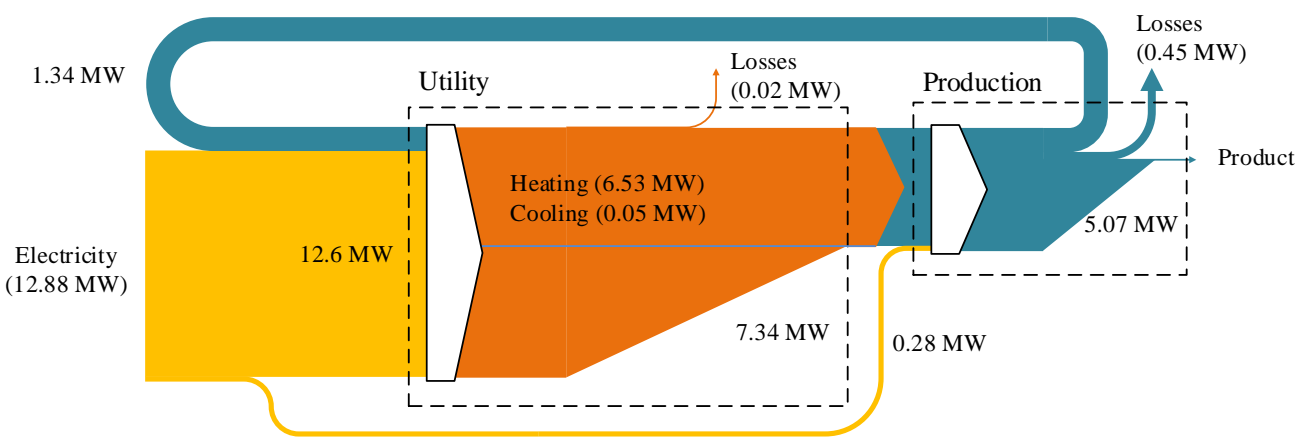

(c) Exergy analysis of electrification scenario 2 (Optimised Processes-Electric Utility)

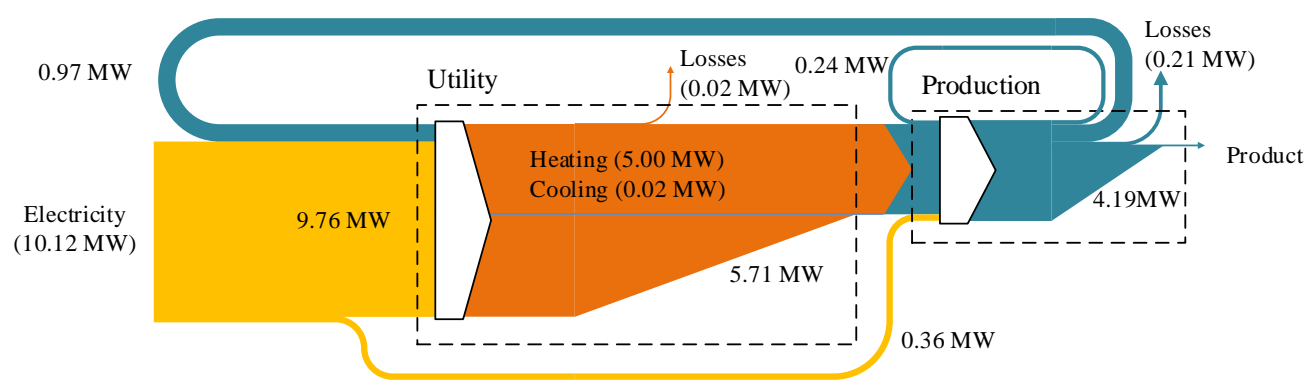

(d) Exergy analysis of electrification scenario 3 (Optimised Processes-Electric Utility)

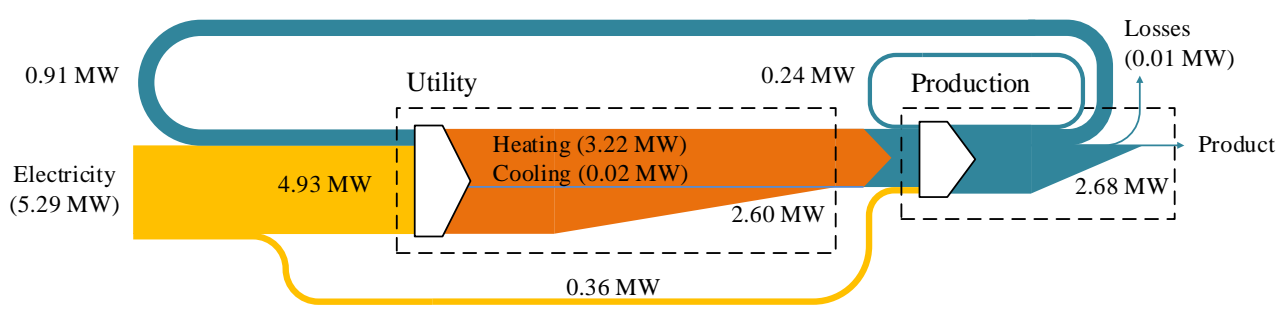

(e) Exergy analysis of electrification scenario 4 (Optimised Processes-Electric Utility)

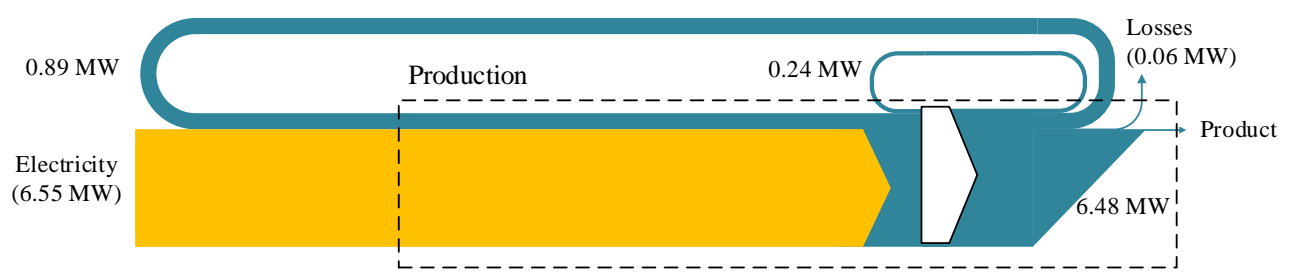

Figure 10: Grassmann diagrams of the milk powder production factory in the different scenarios. 
The exergy product is in all scenarios the same ( $3.43 \mathrm{~kW})$. This is negligible compared to the losses and irreversibilities of the system. However, the exergy input to the production is reduced in scenario 4 and 5 , compared to Scenario 3, as the heating and cooling are delivered at closer conditions to the process stream than in the central utility solution.

\subsection{Economic analysis}

The economic evaluation was used to analyse the feasibility of the electrification scenarios of energy price forecasts for Germany and Denmark and the general relation of economic feasibility with respect to electricity and natural gas prices. These price variations can be seen as a sensitivity analysis, as a constant energy price was assumed over the lifetime. The investments in electrification scenario 4 were analysed in more detail. In Figure 11, the results for Germany and Denmark are shown. The economic analysis showed that Scenario 1 and 2 are not economically profitable, considering the current energy prices in both countries. Under the forecasted energy prices in Germany and Denmark, the investment in either the central or decentral scenarios can become profitable and lead to a positive NPV over the assumed 20 year lifetime. With the analysed prices, scenario 3 performs slightly better than scenario 4 . In general, the investment costs become negligible when natural gas prices approach the price for electricity as the energy use is considerable and becomes the dominating factor. The positive NPV is however caused by the high savings from the energy efficiency measures and the implementation of the MVR. These high savings cause the overall investment in electrification to yield positive NPVs. In the 2030 case for Denmark the NPV for the WHR is 3.2 Mio. $€$ and for the MVR it is 4.8 Mio. $€$. The electric boiler in scenario 2, thus has a negative NPV of almost 24 Mio. $€$.

The distribution of the specific costs of the scenarios over their lifetime and per ton of product is shown in Figure 12 for Denmark and Germany in 2020 and 2030. For the specific costs only milk powder was considered as a product, while cream was considered as a by-product. The investment costs for electric boilers over the lifetime are negligible considering the operation costs, while the investment costs for the heat pump account for between $15 \%$ and almost $30 \%$ of the costs. For Denmark in 2020 and Germany in 2030, the specific costs of all electrified solutions are higher than for the base case (Scenario 0). The addition of a $\mathrm{CO}_{2}$ allowances on natural gas could make the electrified solutions with heat pumps more attractive. 

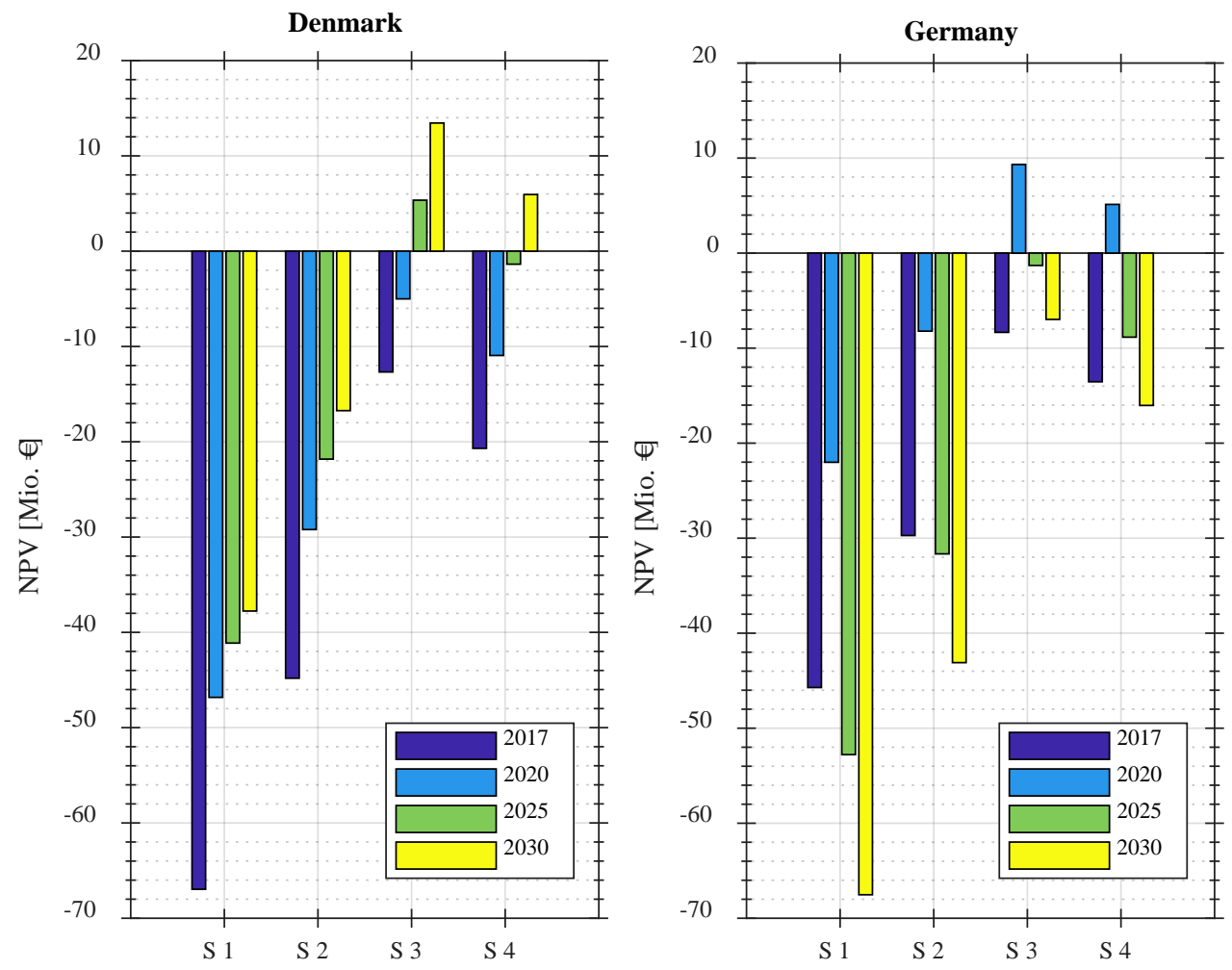

Figure 11: Comparison of the net present value for different years and scenarios for energy prices in Denmark and Germany.

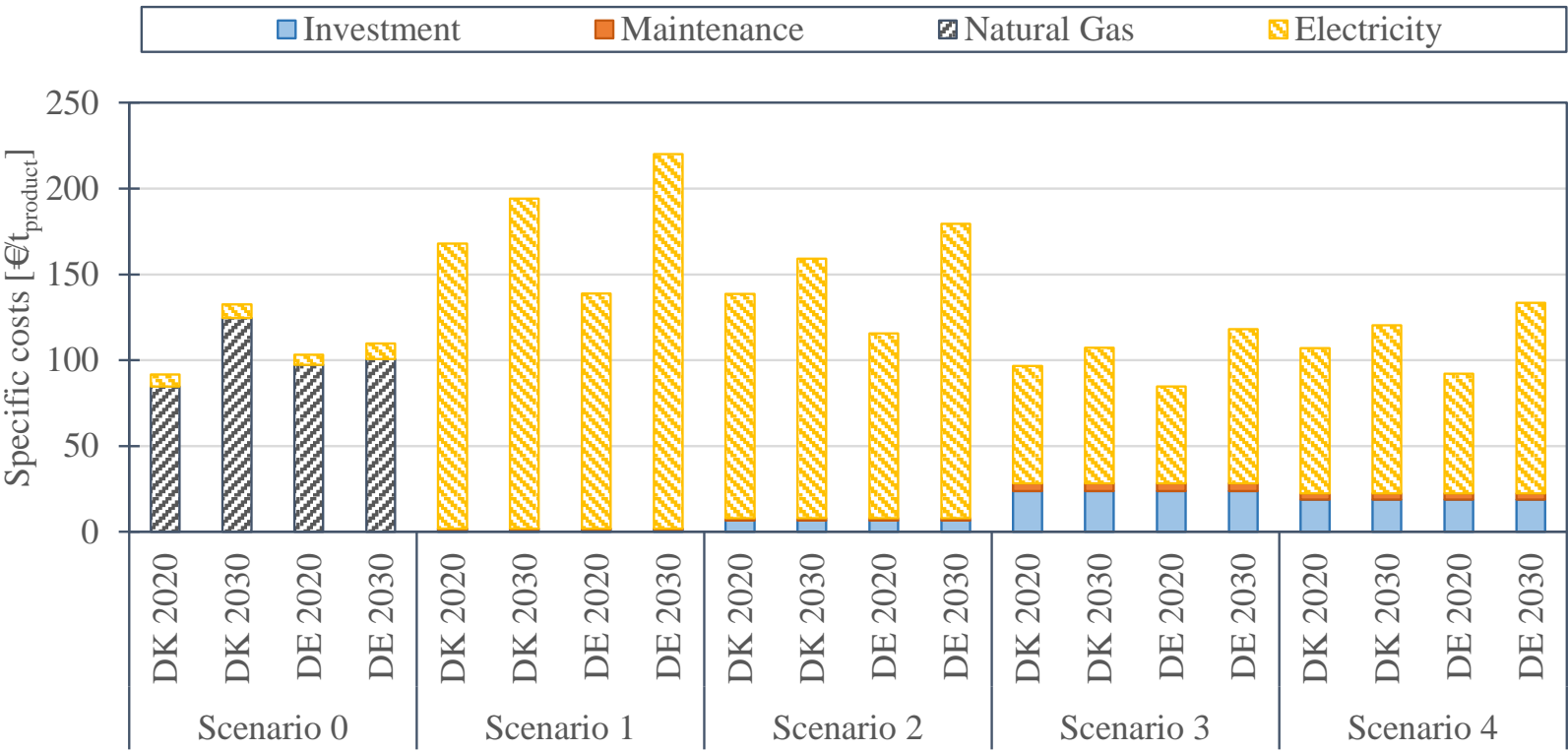

Figure 12: Levelised specific costs of the base and electrification scenarios per ton of milk powder produced.

When generalising the economic analysis and considering a wide range of combination of electricity and natural gas prices (Figure 13), it can be seen that for scenario 1 the natural gas price must almost be equal to the electricity price to make this option viable. By introducing energy efficiency measures, this price ratio is further increased (Scenario 2). When introducing heat pumps, this ratio can be even higher. 
For natural gas prices paid by large industrial consumers within the EU-28 (between $0.025 € / \mathrm{kWh}$ and $0.035 € / \mathrm{kWh}$ ) [43], the ratio of electricity to natural gas price must accordingly be between 1.0 and 1.6 for scenario 3 to be economically feasible over 20 years. For scenario 4 this ratio can be higher, between 1.6 and 1.8, meaning that electricity prices can be higher. Scenario 4 has a lower efficiency but also lower investment costs than scenario 3, which results in faster profitability for certain ratios. On the long run, as shown for the case of Denmark and Germany, the more efficient central system will yield higher NPVs. Similarly, the scenarios with electric boilers obtain a positive NPV at low energy prices quicker than the heat pump solutions, despite being energy-wise considerably less efficient.

For large companies it might be an option to invest in their own renewable energy generators, such as wind power or photovoltaic solar panels to produce electricity, or produce biogas or synthetic natural gas. The levelised costs of energy production of large photovoltaic plants ranged between $38 € / \mathrm{MWh}$ to $76 € / \mathrm{MWh}$ in 2017 and are expected to decrease to between $22 € / \mathrm{MWh}$ and $42 € / \mathrm{MWh}$ by 2030 [47,48]. The prices for onshore wind energy in Denmark are forecasted to decrease in the same time period from $34 \mathrm{€} / \mathrm{MWh}$ to $27 € / \mathrm{MWh}$, while the price levels in Germany for onshore wind energy are higher, between $40 € / \mathrm{MWh}$ and $81 € / M W h$ in 2017. These costs would in particular for the electricity prices after 2020, make the electrified solutions more competitive and allow for higher profits. In particular the onshore wind energy prices and the 2030 prices for photovoltaic would reduce the costs for electricity considerably.

On the other hand, the industrial site could replace natural gas with biogas, either bought or produced on site. The production prices in Denmark were found to be $64 € / \mathrm{MWh}$ for normal biogas and $75 € / \mathrm{MWh}$ for upgraded biogas, using the average biomass composition as a source for the gasification [49,50]. This price was subsidised in 2017 with $18 € / \mathrm{MWh}$, if the biogas was used for process heating. With the unsubsidised prices, electrification scenario 3 and 4 would always be more profitable in the investigated electricity price range ( $<150 € / \mathrm{MWh}$ ). In scenario 2 an electricity price of maximum $90 € / \mathrm{MWh}$ would be required to make the electrification more profitable than normal biogas, which is higher than the predicted price for Germany and Denmark until 2030. A comparable maximum electricity price is found for scenario 3 and 4 when considering the biogas subsidy. 

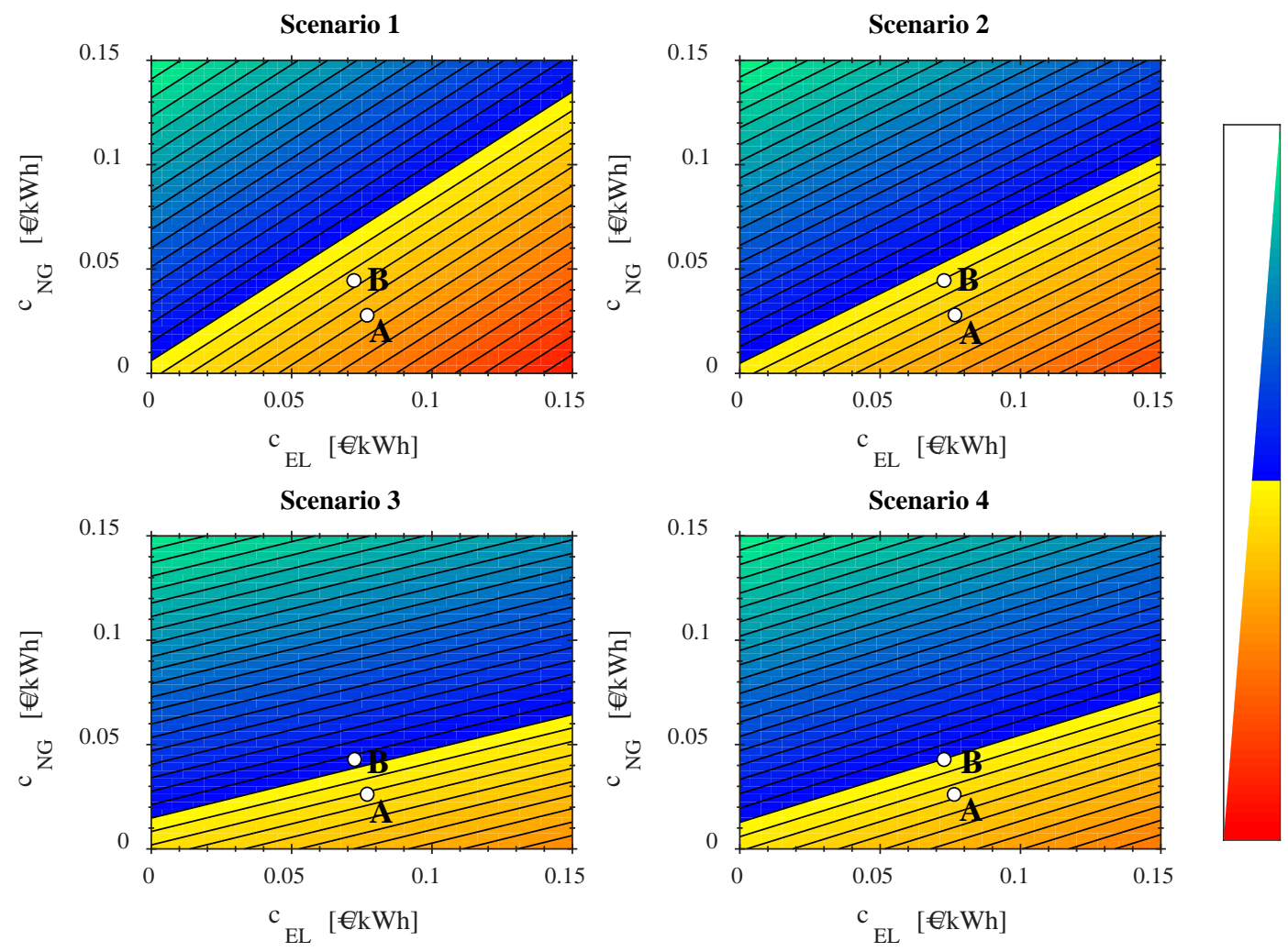

Figure 13: Net present value for a variation of electricity and natural gas prices. “A” marks energy prices in Denmark in 2017 and "B” marks the expected prices in Denmark in 2030.

An advantage of a decentral integration of electric utilities is the possibility to implement cost-efficient options independent of other inefficient ones. In Figure 14 the marginal cost curve for the individual options of electrification scenario 4 is shown for the years 2020 and 2030. The annual costs were calculated following Eq. (10) and include investment costs and savings from reduced natural gas and ice water use. The combination of waste heat recovery through process integration (WHR) and an MVR yield savings already from 2020. The installation of heat pumps HP3, HP4 and HP5 would likewise reduce the annual costs over 20 years. In 2030, all measures, except for the electric heater and HP2, become profitable. Despite the heat pump HP2 being used to supply heating and cooling the low COP and high specific investment costs make this heat pump an unprofitable investment. The large heat pump for preheating the drying air (HP7) allows for considerable savings in operating costs due to comparably low investment costs and high natural gas savings. However, the electric heater accounts in both years for additional annual costs of approximately 1 million Euros. In this case a further reduction in the electricity to natural gas price ratio or the use of a high-temperature heat pump would be necessary to make this a cost-effective option. 

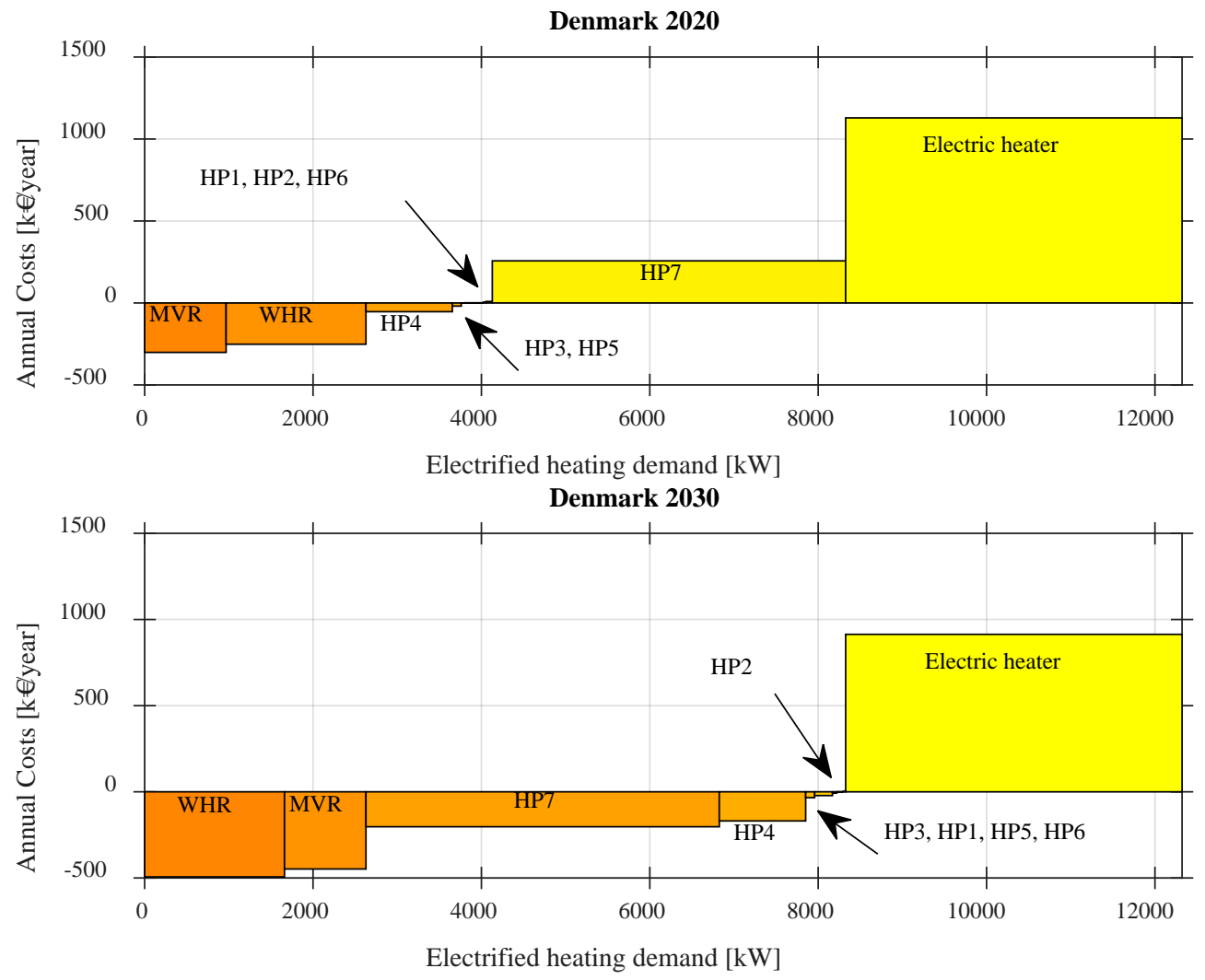

Figure 14: Marginal cost curves of scenario 4 for the year 2020 and 2030 in Denmark. All prices are on a 2017 level and refer to the net level annual costs compared to the base scenario.

\subsection{Environmental evaluation}

In the following the $\mathrm{CO}_{2}$-emissions of energy supply of the dairy factory for the different scenarios are compared (Figure 15). The results show that the heat pump scenarios have the potential to reduce the local $\mathrm{CO}_{2}$-emissions by $50 \%$ in almost all cases. The optimised and electrified solution (Scenario 3) would already allow reducing $\mathrm{CO}_{2}$-emissions compared to the base scenario, despite the lower $\mathrm{CO}_{2}$-emission factor of natural gas compared to the one of electricity in the DK-CHP and EU-28 scenario. An increase in CHP and more renewable energy sources reduce the specific $\mathrm{CO}_{2}$-emissions in future scenarios, compared to the one of natural gas. 


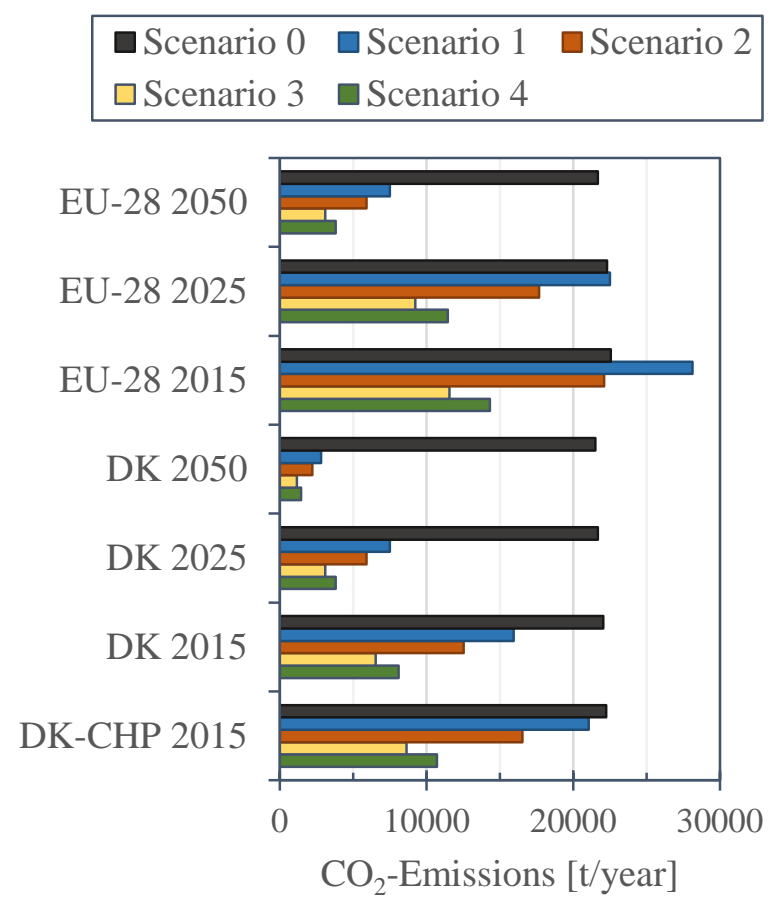

Figure 15: Comparison of annual CO2 emissions of the scenarios for Denmark (DK) and the European Union 28 (EU28) following the EU Reference Scenario 2016 and for DK-CHP the allocation of emission in cogeneration plants.

\section{Discussion}

The central utility was designed using state-of-the-art equipment for the bottom heat pump cycles and partly for the steam compression unit. The first two stages were demonstrated for condensation temperatures up to $150{ }^{\circ} \mathrm{C}$ [29,51] while an extension to three stages and condensation temperatures of $210{ }^{\circ} \mathrm{C}$ to $220^{\circ} \mathrm{C}$ is technically feasible. The decentral and bottom heat pumps in scenario 3 and 4 considered hydrocarbons as working fluids due to their good thermodynamic performance. As their flammability might constitute an issue for industrial sites, they might, depending on the temperature levels, be replaced by R-717 (Ammonia) or hydrofluoroolefins [52,53]. In scenario 3 and 4, ambient air was further used as the source for the heat pump. This cooling capacity could be used to provide cold air for cold storages. The heat pumps were further not fully optimised, which could lead to increased COPs and higher energy efficiency of the scenarios.

In scenario 4 the drying air was heated to the final temperature of $210^{\circ} \mathrm{C}$ by use of an electric heater, although the excess heat in the dryers exhaust gases remained unused. A high temperature heat pump could be implemented here, as it was done in scenario 3. However, the aim of scenario 4 was to use existing technologies which could be implemented close to the production with limited efforts for factory changes and to minimise interdependencies between processes. This would not necessarily be the case for the high-temperature heat pump. An alternative scenario could be the use of individual air-source heat pumps for process heating. These heat pumps would have the same benefits as in scenario 4, without creating interdependencies between cooling and heating demands.

The exergy analysis was used as an important tool to compare the electrification scenarios and compare it to the base case. It was found that the exergy destruction could be reduced considerably by electrifying, and it was lowest for the central heat pump system. The specific energy use for scenario 3 was found to be 0.86 MWh per ton milk powder and 1.06 MWh per ton milk powder for scenario 4 . These values are slightly higher than the thermal energy use of 0.59 MWh and electric energy use of 0.15 MWh per ton of milk found for the best configuration only considering the production in [15]. The best configuration was more advanced 
and also considered improvements to the spray dryer, reverse osmosis for pre-concentration and direct steam injection for pasteurization. The additional pasteurization before the evaporator and the spray dryer were not included, however electric energy use for process pumps was. The integration of direct steam injection for pasteurization could however be an additional energy efficiency measure in scenarios where steam is used and the pre-concentration of milk using reverse osmosis is an alternative electrification measure.

The economic analysis showed that all electrification scenarios can be feasible under specific conditions with respect to energy prices. This was studies as part of a sensitivity analysis with varying energy prices. In particular the two scenarios with heat pumps are expected to be feasible options for energy prices after 2020. Not all possible costs for the investment, such as new piping, were considered. However part of these costs were indirectly included through the conversion of bare module costs to the TCI. The requirement for new piping for instance will be different across the scenarios, however. The investment costs therefore have a degree of uncertainty, which is expected to have a low impact on the net present value as investment costs become overall less important for low energy prices or small price differences between natural gas and electricity. The unit costs for investments in small heat pumps are particularly high, as the applied cost functions have high specific costs for small components. The use of standard components for these heat pumps could reduce the investment costs significantly.

The willingness to accept high investment costs is probably the highest for the central heat pump system (scenario 3), as it is an investment in the main utility of the plant. The decentral electrification strategy considers the implementation of heat pumps which might be affected by process changes, resulting in lower accepted payback times. However, it is possible to prioritise projects with a high return on the investment and to break down the costs for electrification into smaller fractions. The use of electric boilers is most attractive for very low energy prices, where the need for highly efficient systems is secondary compared to the total investment costs. Electric boilers create no considerable technology lock-in, as they are comparably cheaper and thereby replaceable and, furthermore, do not require changes to utility infrastructure and processes. The central heat pump system requires certainty of future process modifications as it is a large investment and requires partly new utility infrastructure. While the decentral heat pumps create the highest technology lockin on a process level, the processes in different production sections are less dependent on each other.

A detailed uncertainty and sensitivity analysis of investment costs and energy prices was not in the scope of this paper. The energy prices and their forecasts are volatile and depend on many factors. Among others, the costs for $\mathrm{CO}_{2}$-emissions ( $\mathrm{CO}_{2}$-certificates) are a parameter which can have great influence on the economic feasibility of the system. If these costs increase for natural gas, the acceptable electricity price will increase progressively in scenario 3 and 4 . In this analysis the minimum temperature difference in the heat exchanger was constant. However, the optimal value depends strongly on the economic boundary conditions, such as the relation between energy prices and investment costs. An optimisation of this temperature difference should thus be performed when the economic boundaries are fixed.

The costs for $\mathrm{CO}_{2}$-emission and energy tax reductions can be even more important for other industries, which e.g. use fuel oil or coal. The electrification strategies proposed and analysed in this paper are however applicable to all process industries. The adoption of these strategies to other sites, should take the proposed method for analysis as the basis.

\section{Conclusion}

In this paper strategies for electrifying industrial processes were presented, which aim to reduce the dependency on fossil fuels commonly used for process heating. The proposed method for electrification consists of modelling and optimising the industrial processes, before evaluating the different strategies for electrification. These considered strategies consist of (i) the conservation of the existing utility infrastructure by using a central electric boiler, (ii) the integration of a central heat pump system using excess and ambient heat sources to supply heating and cooling at different temperature levels and (iii) the use of decentral heat pumps and electric heaters to provide heating and cooling at a process level. The method and the electrification 
strategies were applied to a milk powder production factory, for which different scenarios were compared using energy, exergy, environmental and economic analyses.

It was shown for the dairy factory that energy input and the exergy destruction were lowest in a configuration using a central heat pump system. The overall COP for supplying process heat was 1.95, while it was 1.57 for the scenario implementing decentral heat pumps and electric heaters. This difference resulted from the heating of drying air, done with an electric heater in the decentral scenario, while it was covered by a high temperature heat pump in the central utility scenario. The use of electric boilers for central steam generation was found to be more efficient in energy and exergy terms than the current natural gas-based system, but to be the least efficient option when considering all electrification scenarios.

Similar findings were obtained for the environmental analysis, which investigated $\mathrm{CO}_{2}$-emission reduction compared to the existing natural gas based system. However all options would considerably decrease $\mathrm{CO}_{2}$-emissions in Denmark from 2025 on, as a high share of wind power in the electricity network is expected. For the EU-28, $\mathrm{CO}_{2}$-emissions would be halved in 2025 for the heat pump based systems, while the emissions of the electric boiler systems are only considerable lower by 2050 .

The economic analysis revealed that for the predicted energy prices in Germany and Denmark, the use of electric boilers would not be beneficial, while the heat pump system obtained a positive net present value after 20 years for investments after 2020. Due to the high level of energy use in the dairy factory, investment costs become less important over the considered investment horizon and the relation between natural gas and electricity prices determines the profitability. As the decentral heat pump system had lower investment costs at a lower efficiency, it was found to yield positive net present values at higher ratios of electricity to natural gas prices when considering current natural gas prices in the EU. The central heat pump system becomes however more profitable if electricity prices increase. At last, one benefit of the decentral heat pump system was that the implementation of heat pumps can be done independently, meaning only the most cost-efficient ones could be implemented. The central heat pump has to be implemented as a whole package.

It is expected that the electrification of industrial processes will be an important research area in the near future. Industrial and high temperature heat pumps will play an important role in this transition, but developments are required for heat pumps reaching temperatures above $150^{\circ} \mathrm{C}$, as they will play a pivotal role in reaching an efficient electrification.

\section{Acknowledgements}

This research project was financially funded by ELFORSK, the research and development fund of the Danish Energy Association, under the project (350-038) "Electrification of processes and technologies in the Danish industry" and by The Danish Council for Strategic Research in Sustainable Energy and Environment, under the project title: "THERMCYC - Advanced thermodynamic cycles utilizing low-temperature heat sources". The authors thank the institutions which shared relevant data and industry knowledge: SAN Electro Heat A/S and Viegand Maagøe A/S. 
Nomenclature

\section{Abbreviations:}

$\begin{array}{llll}\text { AP } & \text { Air to product ratio } & \text { GCC } & \text { Grand composite curve } \\ \text { B } & \text { Bottom } & \text { HP } & \text { Heat pump } \\ \text { BAU } & \text { Business as usual } & \text { HU } & \text { Hot utility } \\ \text { c } & \text { Condensing } & \text { IC } & \text { Intercooler } \\ \text { COP } & \text { Coefficient of performance } & \text { IW } & \text { Ice water } \\ \text { CEPCI } & \text { Chemical engineering plant cost } & \text { l } & \text { Liquid state } \\ & \text { index } & \text { LMTD } & \text { Log mean temperature difference } \\ \text { CHP } & \text { Combined heat and power } & \text { MVR } & \text { Mechanical vapour recompression } \\ \text { CU } & \text { Cold utility } & \text { P } & \text { Pump } \\ \text { DK } & \text { Denmark } & \text { T } & \text { Top } \\ \text { DP } & \text { Dew point } & \text { TC } & \text { Turbo compressor } \\ \text { E-H } & \text { Electric heater } & \text { TVR } & \text { Thermal vapour recompression } \\ \text { g } & \text { Gaseous state } & \text { WHR } & \text { Waste heat recovery }\end{array}$

\section{Latin Symbols:}

$\begin{array}{ll}A & \text { Heat exchange area, } \mathrm{m}^{2} \\ C & \text { Specific cost, } € / \mathrm{MWh} \\ C & \text { Costs, } € \\ \mathrm{CF} & \text { Annual cash flow, } € / \text { year } \\ \mathrm{COP} & \text { Coefficient of performance, - } \\ c_{p} & \text { Specific heat capacity, } \mathrm{kJ} /(\mathrm{kg} \mathrm{K}) \\ \mathrm{CRF} & \text { Capital recovery factor, } 1 / \text { year } \\ d & \text { Discount rate, \% } \\ \dot{E} & \text { Exergy flow rate, } \mathrm{kJ} / \mathrm{s} \\ f_{\mathrm{m}} & \text { Material factor, - } \\ h & \text { Specific enthalpy, } \mathrm{kJ} / \mathrm{kg} \\ H & \text { Annual operating hours, h/year } \\ \dot{H} & \text { Enthalpy flow rate, } \mathrm{kJ} / \mathrm{s} \\ i_{\text {eff }} & \text { Effective interest rate, \% } \\ i & \text { Inflation rate, \% }\end{array}$

$k$

$\dot{m}$

$n$

$N$

NPV

PBT

$\dot{Q}$

TCI

$S$

$T$

$U$

$\dot{W}$

$x$

$\Delta T$

Exergy efficiency, -

Energy efficiency, -
Cost function parameter, Mass flow rate, kg/s

Year, year

Lifetime, years

Net present value, $€$

Payback time, years

Heat flow rate, $\mathrm{kW}$

Total capital investment cost, $€$

Specific entropy, $\mathrm{kJ} / \mathrm{kg}$

Temperature, ${ }^{\circ} \mathrm{C}$ or $\mathrm{K}$

Overall heat transfer coefficient, $\mathrm{kW} /\left(\mathrm{m}^{2} \mathrm{~K}\right)$

Work, kW

Size parameter, -

Temperature difference, $\mathrm{K}$

\section{Sub- and Superscripts:}

0

C

D

EL

$\mathrm{h}$

in
At reference condition

Cooling

Destruction

Electricity

Heating

Into the system
Lor

$\min$

NG

out

$\mathrm{P}$

S
Lorenz

Minimum

Natural gas

Out of the system

Purchased equipment

Source 


\section{References}

[1] Danish Ministry of Climate Energy and Building. Energy agreement 2018 [In Danish: Energiaftale 2018]. 2018.

[2] Danish Energy Agency. Energy statistics 2016 [In Danish: Energistatistik 2016]. 2017.

[3] Danish Energy Agency. Energiscenarier frem mod 2020, 2035 og 2050 (Energy scenarios towards 2020, 2035, and 2050) 2014:5. doi:ISBN: 978-87-93071-64-3.

[4] Beyond Zero Emissions. Zero Carbon Industry Plan: Electrifying Industry. Melbourne: 2018.

[5] Mai TT, Jadun P, Logan JS, McMillan CA, Muratori M, Steinberg DC, et al. Electrification Futures Study: Scenarios of Electric Technology Adoption and Power Consumption for the United States. Golden, CO: 2018. doi:10.2172/1459351.

[6] Wiese F, Baldini M. Conceptual model of the industry sector in an energy system model: A case study for Denmark. J Clean Prod 2018;203:427-43. doi:10.1016/j.jclepro.2018.08.229.

[7] Danish Agriculture \& Food Council. Danish Dairy Industry 2015. http://www.agricultureandfood.dk/Danish_Agriculture_and_Food/Danish_dairy_industry.aspx\# (accessed May 27, 2015).

[8] Ramirez C, Patel M, Blok K. From fluid milk to milk powder: Energy use and energy efficiency in the European dairy industry. Energy 2006;31:1984-2004. doi:10.1016/j.energy.2005.10.014.

[9] Yildirim N, Genc S. Energy and exergy analysis of a milk powder production system. Energy Convers Manag 2017. doi:10.1016/j.enconman.2017.01.064.

[10] Yildirim N, Genc S. Thermodynamic analysis of a milk pasteurization process assisted by geothermal energy. Energy 2015;90:987-96. doi:10.1016/j.energy.2015.08.003.

[11] Bühler F, Nguyen T Van, Jensen JK, Holm FM, Elmegaard B. Energy, exergy and advanced exergy analysis of a milk processing factory. Energy 2018;162:576-92. doi:10.1016/j.energy.2018.08.029.

[12] Bühler F, Nguyen T-V, Elmegaard B, Modi A. Process and Economic Optimisation of a Milk Processing Plant with Solar Thermal Energy. Proc. 26th Eur. Symp. Comput. Aided Process Eng., vol. 38, 2016, p. 1347-452. doi:10.1016/B978-0-444-63428-3.50229-0.

[13] Zühlsdorf B, Bühler F, Mancini R, Cignitti S, Elmegaard B. High Temperature Heat Pump Integration using Zeotropic Working Fluids for Spray Drying Facilities. Proc. 12th IEA Heat Pump Conf. 2017, 2017.

[14] Tveit T-M. Application of an industrial heat pump for steam generation using district heating as heat source. 12th IEA Heat Pump Conf Rotterdam, Netherlands 2017:1-9.

[15] Walmsley TG, Atkins MJ, Walmsley MRW, Philipp M, Peesel RH. Process and utility systems integration and optimisation for ultra-low energy milk powder production. Energy 2018;146:67-81. doi:10.1016/j.energy.2017.04.142.

[16] Walmsley MRW, Walmsley TG, Atkins MJ, Neale JR. Sustainable milk powder production using enhanced process integration and $100 \%$ renewable energy. Chem Eng Trans 2016;52:559-64. doi:10.3303/CET1652094.

[17] Pennartz F. An all-electric sustainable slaughterhouse, relying on heat pumps for its heat. Dutch Heat Pump Technol J 2017;2:15-6.

[18] Wiertzema H, Åhman M, Harvey S. Bottom-up methodology for assessing electrification options for deep decarbonisation of industrial processes. Eceee Ind Summer Study Proc 2018:389-97.

[19] Berghout N, Meerman H, van den Broek M, Faaij A. Assessing deployment pathways for greenhouse gas emissions reductions in an industrial plant - A case study for a complex oil refinery. Appl Energy 2019;236:354-78. doi:10.1016/j.apenergy.2018.11.074.

[20] Chen C, Lu Y, Banares-Alcantara R. Direct and indirect electrification of chemical industry using methanol production as a case study. Appl Energy 2019;243:71-90. doi:10.1016/j.apenergy.2019.03.184. 
[21] Linnhoff B, Hindmarsh E. The pinch design method for heat exchanger networks. Chem Eng Sci 1983;38:745-63. doi:10.1016/0009-2509(83)80185-7.

[22] Smith R. Chemical process design and integration. John Wiley \& Sons; 2005.

[23] Klemeš JJ. Handbook of Process Integration ( PI ). Cambridge: Woodhead Publishing Limited; 2013.

[24] Atkins MJ, Walmsley MRW, Neale JR. Integrating heat recovery from milk powder spray dryer exhausts in the dairy industry. Appl Therm Eng 2011;31:2101-6. doi:10.1016/j.applthermaleng.2011.03.006.

[25] Bejan A, Tsatsaronis G, Moran M. Thermal design and optimization. Wiley-Interscience; 1996.

[26] Singh RP, Heldman DR. Introduction. Introd to Food Eng 2014:1-64. doi:10.1016/B978-0-12-3985309.00001-2.

[27] Granryd E, Ekroth I, Lundquist P, Melinder A, Palm B, Rohlin P. Refrigeration Engineering. Stockholm: Department of Energy Technology Division of Applied Thermodynamics and Refrigeration Royal Institute of Technology, KTH; 2009.

[28] Meroni A, Zühlsdorf B, Elmegaard B, Haglind F. Design of centrifugal compressors for heat pump systems. Appl Energy 2018;232:139-56. doi:10.1016/J.APENERGY.2018.09.210.

[29] Bantle M. Turbo-compressors : Prototype tests of mechanical vapour re-compression for steam driers. Proc. 12th IEA Heat Pump Conf. 2017, Rotterdam, 2017, p. Paper ID: O.3.5.4.

[30] Elmegaard B, Zühlsdorf B, Reinholdt L, Bantle M. Book of presentations of the International Workshop on High Temperature Heat Pumps 2017.

[31] Ommen TS, Jensen JK, Markussen WB, Reinholdt L, Elmegaard B. Technical and Economic Working Domains of Industrial Heat Pumps : Part 1 - Vapour Compression Heat Pumps. Int J Refrig 2014;55:18. doi:10.1016/jri.2015.jirefg.02.012.

[32] VDI-Gesellschaft Verfahrenstechnik und Chemieingenieurwesen (GVC). VDI Heat Atlas. vol. 1. 2nd ed. Berlin, Heidelberg: Springer; 2010. doi:10.1007/978-3-540-77877-6.

[33] Périn-Levasseur Z. Energy efficiency and conversion in complex integrated industrial sites. Ecole polytechnique fédérale de Lausanne, 2009. doi:10.5075/EPFL-THESIS-4433.

[34] Tock L, Gassner M, Maréchal F. Thermochemical production of liquid fuels from biomass: Thermoeconomic modeling, process design and process integration analysis. Biomass and Bioenergy 2010;34:1838-54. doi:10.1016/J.BIOMBIOE.2010.07.018.

[35] Turton R, Bailie RC, Whiting WB, Shaeiwitz JA, Bhattacharyya D. Analysis, Synthesis, and Design of Chemical Processes. Fourth. Pearson Education, Inc.; 2012.

[36] Ulrich GD, Vasudevan PT. Chemical Engineering Process Design and Economics: A Practical Guide. second. Durham, New Hampshire: Process Publishing Company; 2004.

[37] Ommen TS, Jensen JK, Markussen WB, Reinholdt L, Elmegaard B. Technical and economic working domains of industrial heat pumps: Part 1 - single stage vapour compression heat pumps. Int J Refrig 2015;55:168-82. doi:10.1016/j.ijrefrig.2015.02.012.

[38] Danish Energy Agency. Technology Data for Energy Plants - Generation of Electricity and District Heating, Energy Storage and Energy Carrier Generation and Conversion. 2015.

[39] Danish Energy Agency. Baseline projection 2018 [In Danish: Basisfremskrivning 2018]. 2018.

[40] PwC (Price Waterhouse Coopers). Overview for the accounting and reimburesment of taxes [In Danish: Samlet overblik over afregning og godtgørelse af afgifter]. 2018.

[41] Danish Energy Agency. Technology data for energy plants - Individual heating plants and energy transport. 2016.

[42] Schlesinger M, Lindenberger D, Lutz C. Development of energy markets - Energy reference forecast [In German: Entwicklung der Energiemärkte - Energiereferenzprognose]. Basel/Köln/Osnabrück: 2014. doi:Projekt Nr. 57/12.

[43] Eurostat. Energy statistics - supply, transformation and consumption 2017. 
http://ec.europa.eu/eurostat/cache/metadata/en/nrg_10_esms.htm (accessed January 20, 2018).

[44] Fleiter T, Fehrenbach D, Worrell E, Eichhammer W. Energy efficiency in the German pulp and paper industry - A model-based assessment of saving potentials. Energy 2012;40:84-99. doi:10.1016/j.energy.2012.02.025.

[45] GEA Process Engineering. Evaporation technology using mechanical vapour recompression. Ettlingen: 2015.

[46] Zühlsdorf B, Bühler F, Bantle M, Elmegaard B. Analysis of technologies and potentials for heat pumpbased process heat supply above $150^{\circ} \mathrm{C}$. Energy Convers Manag 2019; Under Revi.

[47] Danish Energy Agency. Finding your cheapest way to a low carbon future: The Danish Levelized Cost of Energy Calculator. Copenhagen: 2017.

[48] Kost C, Shammugam S, Jülch V, Nguyen H-T, Schlegl T. Levelized cost of electricity renewable energy technologies. Freiburg: 2018.

[49] Ea Energianalyse. Utilisation of biogas for electricity and heat production [In Danish: Anvendelse af biogas til el-og varmeproduktion]. Copenhagen: 2014.

[50] Danish Energy Agency. Biogas in Denmark- status, barriers and perspectives [In Danish: Biogas i Danmark-status, barrierer og perspektiver]. Copenhagen: 2014.

[51] Zühlsdorf B, Schlemminger C, Bantle M, Evenmo K, Elmegaard B. Design Recommendations for R718 Heat Pumps in High Temperature Applications. Proc. 13th IIR Gustav Lorentzen Conf. Nat. Refrig., Valencia: 2018. doi:10.18462/iir.gl.2018.1367.

[52] Bamigbetan O, Eikevik TM, Nekså P, Bantle M, Schlemminger C. Theoretical analysis of suitable fluids for high temperature heat pumps up to $125{ }^{\circ} \mathrm{C}$ heat delivery. Int J Refrig 2018;92:185-95. doi:10.1016/j.ijrefrig.2018.05.017.

[53] Arpagaus C, Bless F, Uhlmann M, Schiffmann J, Bertsch SS. High temperature heat pumps: Market overview, state of the art, research status, refrigerants, and application potentials. Energy 2018;152:985-1010. doi:10.1016/j.energy.2018.03.166.

[54] Bundesministerium für Wirschaft und Technologie. Renewable Energy Sources Act (EEG 2017). 2016. 


\section{Appendix}

The assumptions for the heat transfer equipment are shown in Table 4. These assumptions are based on ranges of values for equipment typically found for the fluids involved. The U-Values are based on ranges given in [32] and the minimum approach temperatures are taken from [33,34] who estimated them based on the heat transfer film coefficient

Table 4: Assumptions for heat transfer equipment.

\begin{tabular}{lllrr}
\hline Component & Fluid 1 & Fluid 2 & \multicolumn{1}{c}{$\Delta T_{\min }$} & \multicolumn{2}{c}{$U$} \\
& & {$[\mathrm{~K}]$} & {$\left[\left(\mathrm{m}^{2} \mathrm{~K}\right)\right]$} \\
\hline Heat Exchanger & Water/ Milk & Water/ Milk & 5.0 & 2500 \\
Heat Exchanger & Water/ Milk & Air & 7.5 & 40 \\
Heat Exchanger & Water/ Milk & Cream & 5.0 & 2000 \\
Heat Exchanger & Air & Air & 10.0 & 23 \\
Evaporator & Water & Refrigerant & 5.0 & 500 \\
Evaporator & Air & Refrigerant & 7.5 & 43 \\
Condenser & Water & Air/ Refrigerant (g) & 7.5 & 40 \\
Condenser & Water & Refrigerant (c) & 5.0 & 1000 \\
Condenser & Water & Refrigerant (l) & 5.0 & 750 \\
Falling Film Evaporator & Water & Solution & 5.0 & 2200 \\
Evaporator/ Condenser & Refrigerant & Refrigerant & 5.0 & 1250 \\
\hline
\end{tabular}

The parameters to be used in cost functions established in Section 2.5 can be found in Table 5. The costs for the equipment found using these cost functions are summarised in Table 7.

Table 5: Parameters for cost functions to be used in Eq. (7).

\begin{tabular}{lrlrrrrr}
\hline Component & \multicolumn{1}{l}{ Range } & \multicolumn{1}{l}{$k_{1}$} & \multicolumn{1}{l}{$k_{2}$} & \multicolumn{1}{c}{$k_{3}$} & Year & $f_{\mathrm{m}}$ & Source \\
\hline Centrifugal/ Reciprocating & $450 \mathrm{~kW}-3000 \mathrm{~kW}$ & 2.2897 & 1.3604 & -0.1027 & 2001 & 2.8 & {$[35]$} \\
Compressors & $10 \mathrm{~kW}-1000 \mathrm{~kW}$ & 3.4756 & 0.6814 & $-8 \cdot 10^{-6}$ & 2004 & 2.2 & {$[36]$} \\
Screw Compressors & $10 \mathrm{~m}^{3} / \mathrm{h}-280 \mathrm{~m}^{3} / \mathrm{h}$ & 2.2477 & 0.7900 & 0 & 2013 & 1.0 & {$[31]$} \\
Reciprocating Piston Compressor & $1 \mathrm{Nm}^{3} / \mathrm{s}-100 \mathrm{Nm}^{3} / \mathrm{s}$ & 3.5391 & -0.3533 & 0.4477 & 2001 & 2.4 & {$[35]$} \\
Centrifugal Radial Fan & $10 \mathrm{~m}^{2}-900 \mathrm{~m}^{2}$ & 3.2476 & 0.2264 & 0.0953 & 2004 & 3.3 & {$[36]$} \\
Shell and Tube Heat Exchanger & $1 \mathrm{~m}^{2}-2000 \mathrm{~m}^{2}$ & 3.1316 & 0.3454 & 0.0823 & 2004 & 3.3 & {$[36]$} \\
Flat plate Heat Exchanger & $1 \mathrm{~m}^{2}-8000 \mathrm{~m}^{2}$ & 3.2195 & 0.3743 & 0.046 & 2004 & 1.0 & {$[36]$} \\
Internal-coils in Evaporator Tank & $28 \mathrm{~m}^{2}-316 \mathrm{~m}^{2}$ & 2.8595 & 0.981 & $-8 \cdot 10^{-6}$ & 2005 & 2.3 & {$[36]$} \\
Falling Film Evaporator & $1 \mathrm{~m}^{2}-800 \mathrm{~m}^{3}$ & 3.5970 & 0.2163 & 0.0934 & 2004 & 3.0 & {$[36]$} \\
Evaporator Plain Vessel & & & & & & &
\end{tabular}

The energy prices used to evaluate the different scenarios for different years and countries and explained in Section 2.5.3 can be found in Table 6 . 
Table 6: Overview of energy prices for industrial process use on a 2017 basis.

\begin{tabular}{|c|c|c|c|c|c|c|c|c|}
\hline Region & Year & $\begin{array}{l}\text { Net Price } \\
{[€ / \mathrm{MWh}]}\end{array}$ & $\begin{array}{l}\text { Electricity } \\
\text { Tax \& Fees } \\
\text { [€/MWh] }\end{array}$ & $\begin{array}{c}\text { Total } \\
\text { [€/MWh] }\end{array}$ & $\begin{array}{l}\text { Net Price } \\
\text { [€/MWh] }\end{array}$ & $\begin{array}{c}\text { Natural Ga } \\
\text { Tax \& } \\
\text { Fees } \\
\text { [€/MWh] }\end{array}$ & $\begin{array}{c}\text { Total } \\
\text { [€/MWh] }\end{array}$ & Reference \\
\hline Denmark & 2017 & 31.3 & 44.9 & 76.2 & 19.5 & 9.3 & 28.9 & [39-41] \\
\hline Denmark & 2020 & 34.5 & 28.6 & 63.1 & 19.4 & 9.3 & 28.8 & [39-41] \\
\hline Denmark & 2025 & 40.8 & 27.2 & 68.0 & 26.8 & 9.3 & 36.2 & [39-41] \\
\hline Denmark & 2030 & 45.8 & 27.2 & 73.0 & 33.0 & 9.3 & 42.3 & [39-41] \\
\hline Germany $^{1}$ & 2017 & 54.2 & 4.3 & 58.4 & 19.9 & 5.5 & 25.4 & [42] \\
\hline Germany $^{1}$ & 2020 & 44.6 & 7.4 & 52.1 & 27.6 & 5.5 & 33.1 & [42] \\
\hline Germany $^{1}$ & 2025 & 63.7 & 9.6 & 73.3 & 28.7 & 5.5 & 34.2 & [42] \\
\hline Germany ${ }^{1}$ & 2030 & 71.2 & 11.7 & 82.9 & 28.7 & 5.5 & 34.2 & [42] \\
\hline Denmark $^{2}$ & 2017 & 47.6 & 21.1 & 68.7 & 23.9 & 9.5 & 33.4 & [43] \\
\hline Germany $^{2}$ & 2017 & 48.1 & 44.9 & 93.0 & 27.2 & 4.1 & 31.2 & [43] \\
\hline EU28 ${ }^{2}$ & 2017 & 60.9 & 22.2 & 83.1 & 25.3 & 3.7 & 28.9 & [43] \\
\hline
\end{tabular}

${ }^{1}$ Prices applicable for electricity intensive industries as defined in [54].

${ }^{2}$ Prices applicable for an electricity use of $20 \mathrm{GWh}$ to $70 \mathrm{GWh}$ and natural gas use of $28 \mathrm{GWh}$ and $278 \mathrm{GWh}$

An overview of the equipment costs for the different scenarios can be found in Table 7.

Table 7: Overview of the equipment costs for the different electrification scenarios. All costs are on a 2017 basis.

\begin{tabular}{ccrrr}
\hline Scenario & Equipment & $\begin{array}{r}\text { Bare Module Costs } \\
{[\mathrm{k} €]}\end{array}$ & $\begin{array}{r}\text { TCI } \\
{[\mathrm{k} €]}\end{array}$ & $\begin{array}{r}\text { Specific TCI } \\
{[€ / \mathrm{kW}]}\end{array}$ \\
\hline Scenario 1 & Electric boiler & 746 & 1,012 & 81 \\
Scenario 2 & Electric boiler & 587 & 789 & 81 \\
Scenario 2 - 4 & MVR & 300 & 407 & 421 \\
Scenario 2 - 4 & WHR & 2,109 & 2,861 & 2,661 \\
Scenario 3 & B-HP1 & 264 & 349 & 978 \\
Scenario 3 & B-HP2 & 193 & 224 & 1,138 \\
Scenario 3 & B-HP3 & 118 & 263 & 722 \\
Scenario 3 & B-HP4 & 945 & 1,362 & 839 \\
Scenario 3 & B-HP5 & 2,722 & 3,694 & 853 \\
Scenario 3 & B-HP6 & 334 & 488 & 1310 \\
Scenario 3 & T_HP & 3,841 & 4,460 & 634 \\
Scenario 3 & Evap & 226 & 307 & - \\
Scenario 4 & HP1 & 1,088 & 191 & 897 \\
Scenario 4 & HP2 & 23 & 56 & 1,775 \\
Scenario 4 & HP3 & 52 & 110 & 1,034 \\
Scenario 4 & HP4 & 288 & 608 & 592 \\
Scenario 4 & HP5 & 94 & 139 & 2,818 \\
Scenario 4 & HP6 & 187 & 266 & 3,548 \\
Scenario 4 & HP7 & 5,389 & 7,313 & 1,742 \\
Scenario 4 & Electric boiler & 242 & 325 & 81 \\
\hline
\end{tabular}


Page $\mathbf{3 7}$ of $\mathbf{3 7}$ 